\title{
Water Group Exospheres and Surface Interactions on the Moon, Mercury, and Ceres
}

\author{
Norbert Schörghofer ${ }^{1,2}$ (D) $\cdot$ Mehdi Benna $^{3}$ (D) Alexey A. Berezhnoy ${ }^{4,5}$ (D)

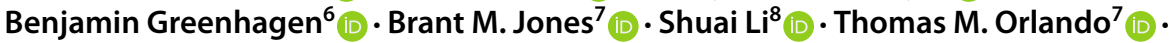 \\ Parvathy Prem $^{6}$ (D) Orenthal J. Tucker ${ }^{3}$ (D) Christian Wöhler $^{9}$ (D)
}

Received: 31 October 2020 / Accepted: 9 August 2021 / Published online: 1 September 2021

(c) The Author(s) 2021

\begin{abstract}
Water ice, abundant in the outer solar system, is volatile in the inner solar system. On the largest airless bodies of the inner solar system (Mercury, the Moon, Ceres), water can be an exospheric species but also occurs in its condensed form. Mercury hosts water ice deposits in permanently shadowed regions near its poles that act as cold traps. Water ice is also present on the Moon, where these polar deposits are of great interest in the context of future lunar exploration. The lunar surface releases either $\mathrm{OH}$ or $\mathrm{H}_{2} \mathrm{O}$ during meteoroid showers, and both of these species are generated by reaction of implanted solar wind protons with metal oxides in the regolith. A consequence of the ongoing interaction between the solar wind and the surface is a surficial hydroxyl population that has been observed on the Moon. Dwarf planet Ceres has enough gravity to have a gravitationally-bound water exosphere, and also has permanently shadowed regions near its poles, with bright ice deposits found in the most long-lived of its cold traps. Tantalizing evidence for cold trapped water ice and exospheres of molecular water has emerged, but even basic questions remain open. The relative and absolute magnitudes of sources of water on Mercury and the Moon remain largely unknown. Exospheres can transport water to cold traps, but the efficiency of this process remains uncertain. Here, the status of observations, theory, and laboratory measurements is reviewed.
\end{abstract}

Keywords Mercury · The Moon · Ceres · Exospheres · Water · Hydroxyl

\section{Introduction}

The abundance of water ice in permanently shadowed craters on the Moon is key to the future exploration of the lunar surface. The underlying idea was formulated a long time ago (Watson et al. 1961a,b): water from exogenic or endogenic sources is transported laterally through the exosphere and then trapped in permanently shadowed regions (PSRs) near the lunar poles. No part of this process has yet been confirmed. The primary source of water

Surface-Bounded Exospheres and Interactions in the Inner Solar System

Edited by Anna Milillo, Menelaos Sarantos, Benjamin D. Teolis, Go Murakami, Peter Wurz and Rudolf von Steiger

Extended author information available on the last page of the article 
on the Moon is unknown. The efficiency of the water exosphere as a transport process is controversial. And studies of the abundance and distribution of ice in lunar PSRs have resulted in divergent answers. What is established is that the cold traps of the planet Mercury are filled with water ice, and cold traps on the Moon contain at least some, but perhaps not much, ice. Research over the last decade has provided a great deal of new information. The MESSENGER spacecraft orbited Mercury from 2012 to 2015. The Lunar Reconnaissance Orbiter (LRO) has continuously provided data since 2009, and the Lunar Atmosphere and Dust Environment Explorer (LADEE) orbited in the equatorial plane of the Moon from 2013 to 2014. The Chandrayaan-1 mission ended in 2009, but some of its measurements have only been analyzed more recently. Ceres, a large asteroid that also has PSRs, was visited by the Dawn spacecraft from 2015 to 2018. These three airless bodies of the inner solar system (Mercury, the Moon, and Ceres) each have (nearly) ice-free surfaces, PSRs, and (at least potentially) gravitationally-bound water exospheres. Here we summarize recent results from orbital measurement campaigns, physical chemistry, and theoretical models about water group exospheres. Some of the measurement techniques do not distinguish between water $\left(\mathrm{H}_{2} \mathrm{O}\right)$ and hydroxyl $(\mathrm{OH})$, so "water group" $\left(\mathrm{OH}\right.$ or $\left.\mathrm{H}_{2} \mathrm{O}\right)$ is a frequently used term in this review.

The surface-bounded exospheres of Mercury and the Moon have been reviewed by Killen and Ip (1999) and Stern (1999). The exosphere and polar deposits of Mercury after MESSENGER have been reviewed by Killen et al. (2018), McClintock et al. (2018), and Chabot et al. (2018a). Reviews of surface volatiles on the Moon are available by Basilevsky et al. (2012) and Hayne et al. (2014). Lawrence (2017) summarizes our understanding of polar volatiles on Mercury and the Moon. Table 1 lists some of the pertinent observational discoveries.

\section{Models of $\mathrm{H}, \mathrm{H}_{2}$, and $\mathrm{OH}$ Interactions on Planetary Surfaces}

Observations of water products bound to airless bodies like the Moon, Mercury, and Ceres are infrequent and possess sparse temporal and global coverage. Therefore, theoretical models are required to understand the driving dynamics and sources of surficial and exospheric water group molecules. Zeller et al. (1966) demonstrated proton-induced hydroxyl formation experimentally. Extraordinary theoretical studies carried out by Starukhina (2001) of solar wind implantation and $\mathrm{H}$ atom diffusion predicted the presence of a widespread $\mathrm{OH} / \mathrm{H}_{2} \mathrm{O}$ IR $2.8 \mu \mathrm{m}$ feature well before it was observed in 2009 (Pieters et al. 2009; Sunshine et al. 2009; Clark 2009). Likewise, Johnson (1971), Hodges (1973) and Hartle and Thomas (1974) carried out pioneering studies that predicted the presence of $\mathrm{H}_{2}$ in the lunar exosphere sourced from the solar wind and primarily lost by thermal escape. In this section we review recent theoretical studies aimed at examining how exogenic hydrogen sources are partitioned within surficial and exospheric inventories of the lunar environment.

\subsection{Surface Diffusion Models}

Starukhina and Shkuratov (2000) predicted that solar wind protons implanted in oxygen bearing regolith become both physically trapped in defects and chemically trapped as $\mathrm{OH}$, based on experimental evidence (e.g., Zeller et al. 1966; Mattern et al. 1976). The solar wind bombardment simultaneously frees trapped hydrogen, which diffuses to the surface and thermally desorbs into the exosphere as $\mathrm{H}_{2}$ (Starukhina 2006). This process can be characterized as a diffusive process and the surface concentration of $\mathrm{OH}$ molecules and the $\mathrm{H}_{2}$ desorption flux are proportional to $\sim \exp \left(-E_{\mathrm{a}} / k T\right)$, where $E_{\mathrm{a}}$ is the activation energy, 
Table 1 Selected observations relevant to water group exospheres and the surface reservoirs they interact with

\begin{tabular}{|c|c|c|c|}
\hline $\begin{array}{l}\text { Planetary } \\
\text { Body }\end{array}$ & $\begin{array}{l}\text { Instrument } \\
\text { or Method }\end{array}$ & $\begin{array}{l}\text { Spacecraft or } \\
\text { Observatory (time } \\
\text { period of data } \\
\text { collection) }\end{array}$ & Major discoveries \\
\hline Mercury & radar & $\begin{array}{l}\text { Goldstone, Arecibo, } \\
\text { and Very Large Array } \\
(1991-1992)\end{array}$ & polar ice deposits \\
\hline Mercury & various & $\begin{array}{l}\text { MESSENGER } \\
(2011-2015)\end{array}$ & $\begin{array}{l}\text { relation between ice and permanently } \\
\text { shadowed regions }\end{array}$ \\
\hline The Moon & neutron spectrometer & $\begin{array}{l}\text { Lunar Prospector } \\
(1998-1999)\end{array}$ & polar regions are enriched in hydrogen \\
\hline The Moon & $\begin{array}{l}\text { near infrared, visible, } \\
\text { UV spectrometers }\end{array}$ & LCROSS (2009) & $\begin{array}{l}\mathrm{H}_{2} \mathrm{O} \text { and } \mathrm{OH} \text { detected in impact plume } \\
\text { above cold trap }\end{array}$ \\
\hline The Moon & $\begin{array}{l}\mathrm{M}^{3} \text { (Moon } \\
\text { Mineralogy Mapper) }\end{array}$ & $\begin{array}{l}\text { Chandrayaan-1 } \\
(2008-2009)\end{array}$ & $\begin{array}{l}\text { diurnal and latitude variation in } \mathrm{OH} \text {-band } \\
\text { strength, } \mathrm{H}_{2} \mathrm{O} \text { exposed in cold traps }\end{array}$ \\
\hline The Moon & Diviner & LRO (2009-now) & detailed mapping of cold traps \\
\hline The Moon & $\begin{array}{l}\text { NMS (Neutral Mass } \\
\text { Spectrometer) }\end{array}$ & LADEE (2013-2014) & $\begin{array}{l}\text { water group exosphere detected, correlates } \\
\text { with meteoroid streams }\end{array}$ \\
\hline Ceres & $\begin{array}{l}\text { Long-wavelength } \\
\text { prime camera }\end{array}$ & $\begin{array}{l}\text { International UV } \\
\text { Explorer (1990-1991) }\end{array}$ & detection of temporary $\mathrm{OH}$ exosphere \\
\hline Ceres & $\begin{array}{l}\text { GRaND and Framing } \\
\text { Camera }\end{array}$ & Dawn (2015-2018) & $\begin{array}{l}\text { ice-rich subsurface, permanently shadowed } \\
\text { regions }\end{array}$ \\
\hline Ceres & far infrared & $\begin{array}{l}\text { Herschel Space } \\
\text { Observatory } \\
(2011-2013)\end{array}$ & detection of temporary $\mathrm{H}_{2} \mathrm{O}$ atmosphere \\
\hline
\end{tabular}

$k$ is the Boltzmann constant and $T$ is the local surface temperature. This interpretation is consistent with the observations of the lunar $\mathrm{OH} / \mathrm{H}_{2} \mathrm{O}$ veneer (Pieters et al. 2009; Sunshine et al. 2009; Clark 2009; Li and Milliken 2017; Wöhler et al. 2017b), further described in Sect. 4.1.

Irradiation of regolith grains leads to a dynamic equilibrium between the formation of dangling bonds (immobile atoms with an unsatisfied valence), which are chemical trapping sites, and diffusing hydrogen (Griscom 1984; Fink et al. 1995; Farrell et al. 2015). Farrell et al. $(2015,2017)$ highlighted that diffusion of hydrogen is best characterized by considering a distribution of activation energies, because exposed grains are known to be defect rich in the top $100 \mathrm{~nm}$ due to the space environment (Noble et al. 2005). They found this approach is qualitatively consistent with the latitudinal trends and diurnal modulation of the observed $2.8 \mu \mathrm{m} \mathrm{OH} / \mathrm{H}_{2} \mathrm{O}$ feature over the lunar surface (Sunshine et al. 2009; McCord et al. 2011). Farrell et al. $(2015,2017)$ review the solution of the continuity equation for the steady state hydrogen surface concentration balanced by the solar wind implantation against diffusive losses and retention in the regolith by formation of $\mathrm{OH}$, and the implementation of Monte Carlo models of $\mathrm{H}$ retention in the surface using a Gaussian distribution of activation energies to characterize diffusion. These models solely considered the steady state concentration of hydrogen, and all surface loitering $\mathrm{H}$ atoms are presumed to be trapped as $\mathrm{OH}$.

Grumpe et al. (2019) adapted the continuity model applied in the Farrell et al. studies to include time dependence, the $\mathrm{OH}$ continuity equations in addition to the $\mathrm{H}$ continuity equation, and the surface photolysis of $\mathrm{OH}$. A micrometeoroid source of $\mathrm{OH}$ and $\mathrm{H}_{2} \mathrm{O}$ was 
also included, but solar wind implantation was found to be the dominant source. The Grumpe et al. continuity model was constrained to the inferred $\mathrm{OH}$ surface densities from Moon Mineralogy Mapper $\mathrm{M}^{3}$ spectra using the thermal correction model applied in Wöhler et al. (2017b), which inferred hydroxyl abundances on order of $1-10 \mathrm{ppm}$ with mild diurnal and latitudinal variations. For comparison, the water concentration in Apollo samples is typically around $40-50 \mathrm{ppm}$ ( $\mathrm{Li}$ and Milliken 2017), but could potentially have been affected by terrestrial contamination. Grumpe et al. (2019) fit the variation of the $3 \mu \mathrm{m}$ band depth versus local time of day to extract the $\mathrm{H}$ diffusion activation energy, $\mathrm{OH}$ photolysis lifetime and region specific $\mathrm{OH}$ activation energies.

\section{$2.2 \mathrm{H}_{2}$ Exospheric Models}

Molecular hydrogen was first detected in the lunar exosphere by the Lyman Alpha Mapping Project (LAMP) UV spectrograph on LRO (Stern et al. 2013), and later confirmed by the Chandrayaan-1 Altitudinal Composition Explorer (CHACE) mass spectrometer (Thampi et al. 2015). Hurley et al. (2017) used an exospheric Monte Carlo model to track the density and spatial distribution of $\mathrm{H}_{2}$ on the Moon produced by micrometeoroid bombardment, solar wind knock-on sputtering and chemical sputtering. Micrometeoroid impacts volatilize implanted hydrogen atoms which may chemically combine as $\mathrm{H}_{2}$ and thermally desorb from the surface at temperatures $>600 \mathrm{~K}$ (Cintala 1992) with a Maxwell Boltzmann flux speed distribution (Brinkmann 1970). Knock-on sputtering occurs via momentum transfer during direct collisions from solar wind ions with regolith atoms and molecules. The sputter ejecta are released from the surface assuming a Sigmund-Thompson energy distribution roughly consistent with sputter theory (Johnson 1990). Hurley et al. (2017) determined that both micrometeoroid vaporization and solar wind sputtering were too energetic to reproduce $\mathrm{H}_{2}$ exospheric densities of $1200 \pm 400 \mathrm{~cm}^{-3}$ observed by LAMP, because the solar wind source of protons is insufficient. Solar wind plasma bombardment also releases physically and chemically trapped $\mathrm{H}$ atoms which diffuse and thermally desorb from the surface as $\mathrm{H}_{2}$ at the local surface temperature with a Maxwell Boltzmann flux speed distribution. This process is referred to as chemical sputtering. Hurley et al. estimated $\mathrm{H}_{2}$ chemical sputtering at rates of $\sim 19 \mathrm{~g} / \mathrm{s}$ consistent with both the LAMP observations and the solar wind source of protons $\sim 31.5 \mathrm{~g} / \mathrm{s}$.

\subsection{Coupled Surface Diffusion - Exospheric Models}

The abundance of water group exospheric gases is directly linked to the subsurface diffusion and chemistry of hydrogen atoms with regolith oxides. Tucker et al. (2019) coupled the Farrell et al. Monte Carlo model (using a distribution of activation energies to characterize $\mathrm{H}$ atom diffusion) to a time dependent global Monte Carlo model of exospheric degassed $\mathrm{H}_{2}$. When applying a Gaussian distribution of diffusive activation energies with a peak centered at $\sim 0.5 \mathrm{eV}$ and width of $\sim 0.1 \mathrm{eV}$ the model simultaneously fit the Moon Mineralogy Mapper $\mathrm{M}^{3}$ latitudinal and diurnal $\mathrm{OH}$ surface concentrations as interpreted from the thermal correction model applied in Li and Milliken (2017), the LAMP $\mathrm{H}_{2}$ exospheric densities $\left(1200 \pm 400 \mathrm{~cm}^{-3}\right)$, and the CHACE exospheric $\mathrm{H}_{2}$ surface densities as a function of latitude $\left(\sim 400 \mathrm{~cm}^{-3}-800 \mathrm{~cm}^{-3}\right.$, latitudes $\left.20^{\circ}-80^{\circ}\right)$ obtained while the Moon was in the geomagnetic tail (Tucker et al. 2021). For a peak activation energy of $0.7 \mathrm{eV}$ the model surface was hydrogen retentive and the surface concentration was a couple of orders of magnitude larger, whereas the exospheric $\mathrm{H}_{2}$ densities were an order of magnitude lower. Likewise, for a peak activation energy of $0.3 \mathrm{eV}$ the surface was hydrogen emissive and significantly underestimated the $\mathrm{Li}$ et al. data at mid to high latitudes. 


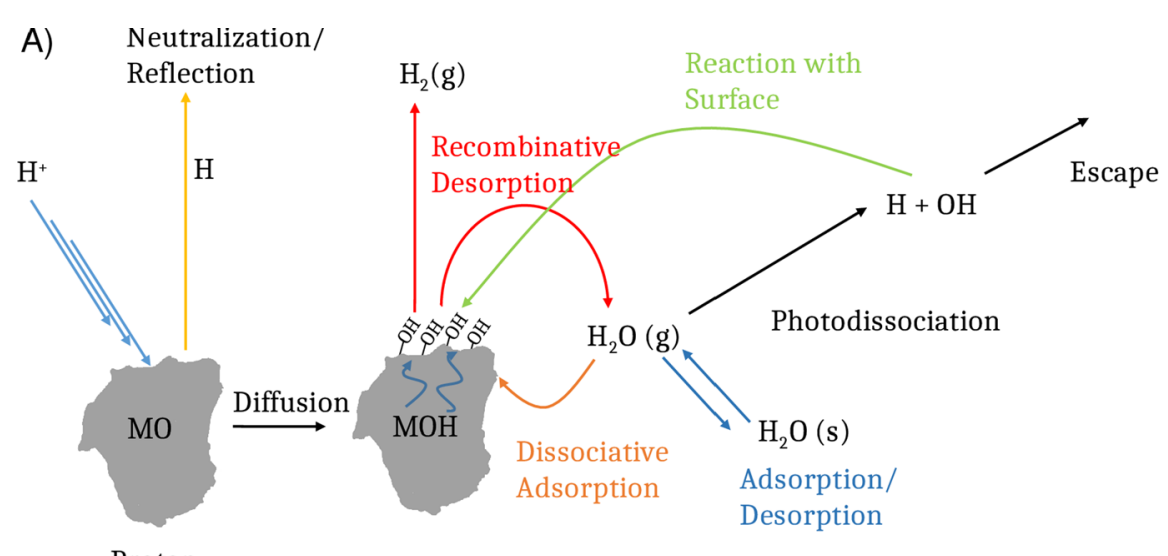

Proton

Implantation

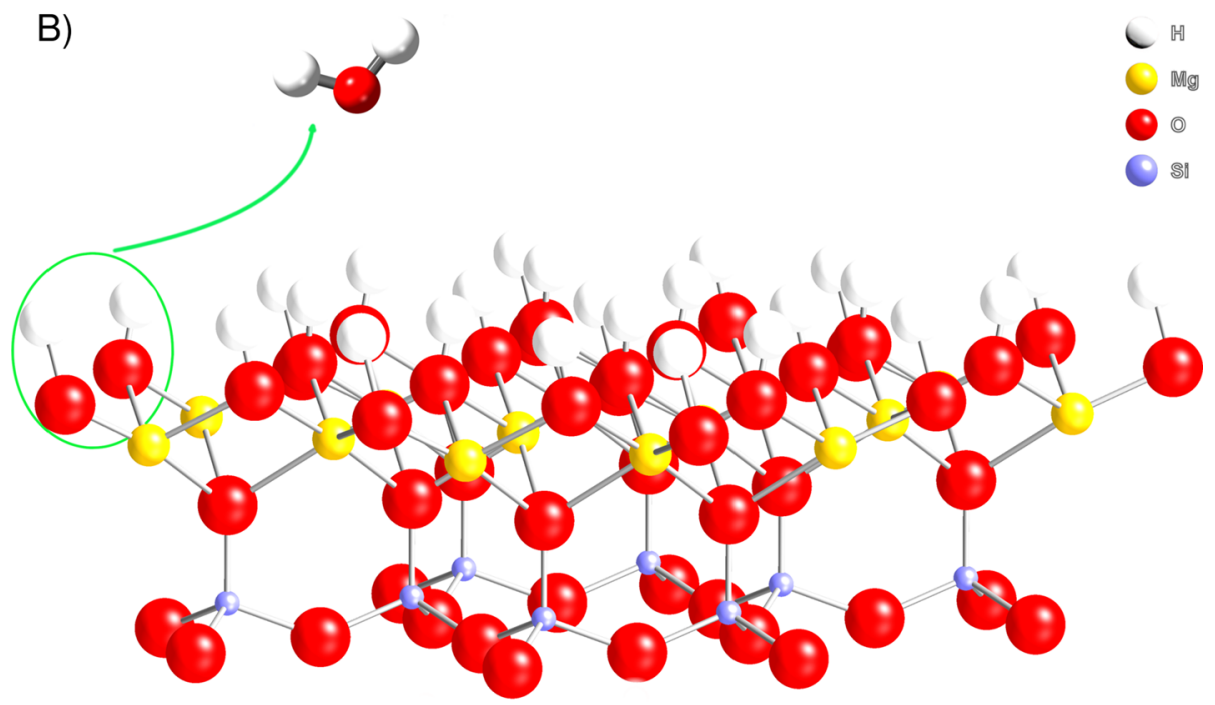

Fig. 1 A) Kinetic scheme for the solar-wind-induced water cycle on the surface of Mercury. B) Illustration of mineral surface of magnesium silicate with saturated hydroxyls. Upon heating, a reaction takes place between neighboring $\mathrm{OH}$ sites (encircled with green) resulting in the formation of gas phase water and an oxygen bridge between cations. Figures adapted from Jones et al. (2020), copyright by AAS

Second order recombinative desorption (RD) of neighboring hydroxyls on surface grains has recently been investigated as an important pathway of gas phase water production on the Moon and other airless bodies (Jones et al. 2018, 2020; Fig. 1), see Sect. 3. Implanted protons react with metal oxides forming bound hydroxyls $(\mathrm{M}-\mathrm{OH}$, where $\mathrm{M}$ represents a metal atom). Over time, the hydroxyl sites diffuse to the surface where they can recombine with other surficial hydroxyls and desorb as gas phase water. RD is not efficient for silicate grains (50 wt $\%$. of the regolith) at temperatures $<600 \mathrm{~K}$, and the maximum surface temperature on the Moon is about $400 \mathrm{~K}$, but such temperatures can be obtained during micrometeoroid impacts. Jones et al. (2018) derived an upper limit for the dayside $\mathrm{H}_{2} \mathrm{O}$ exospheric density 
of $60 \mathrm{~cm}^{-3}$, consistent with the abundances inferred from LADEE measurements, described in Sect. 5 below.

At Mercury the dayside temperatures at local noon exceed $600 \mathrm{~K}$, and RD may be an important process for $\mathrm{H}_{2} \mathrm{O}$ production and transport of water to polar cold traps (Jones et al. 2020). Jones et al. developed a forward model by using the degassed $\mathrm{H}_{2} \mathrm{O}$ flux from a surface diffusive-kinetic Monte Carlo model of OH RD in an exospheric transport Monte Carlo model of $\mathrm{H}_{2} \mathrm{O}$ to examine its transport to the poles. The model predicts a global $\mathrm{H}_{2} \mathrm{O}$ degassing rate of $3 \times 10^{30}$ molecules per Mercury day $(4 \mathrm{~g} / \mathrm{s})$. At this source rate, RD is a constant replenishing source of water to the poles and cold traps, and could account for a significant portion of the total water mass trapped as ice over geological time periods, supplementing other potential sources such as comets and meteoroid impacts.

\section{Hydroxylation \& in-Situ Generation of $\mathrm{H}_{2} \mathrm{O}$}

Potential sources of lunar water group species $\left(\mathrm{H}_{2} \mathrm{O}\right.$ and $\left.-\mathrm{OH}\right)$ include: primordial water (Hui et al. 2013; Robinson et al. 2016), water delivered via comets and meteoroids (Arnold 1979; Greenwood et al. 2011) and captured during the impact event (Daly and Schultz 2018; Stopar et al. 2018), and implantation from solar wind (Zeller et al. 1966). A prevalent mechanism for the formation of molecular water on the surfaces of airless bodies may be a thermally activated process known as recombinative desorption (RD) or associative desorption (AD) of hydroxyl $(-\mathrm{OH})$ defects that were made by implantation of solar wind protons.

The formation of chemically bound hydroxyls is a well-known consequence of proton implantation (Zeller et al. 1966; Mattern et al. 1976; Burke et al. 2011; Ichimura et al. 2012; Managadze et al. 2011; Schaible and Baragiola 2014). These solar wind implanted hydroxyls are attributed to the infrared absorption feature centered at $2.8 \mu \mathrm{m}$ observed on the lunar surface (McCord et al. 2011). Over time, the implanted OH defect sites will diffuse to the surface of the regolith grain in a relatively short amount of time with respect to the planetary and lunar rotation timescales, e.g., within a few lunar hours given the $\mathrm{OH}$ diffusion constants (Starukhina and Shkuratov 2000).

Following the buildup of terminal hydroxyl sites on the regolith grain, water can form through RD. Here, RD is a surface-mediated process that describes a chemical reaction between neighboring or interacting termination sites followed by desorption of the molecular product. For example, consider neighboring species representing dangling $\mathrm{M}-\mathrm{OH}$ bonds ( $\mathrm{M}$ being a generic metal cation, e.g., $\mathrm{Si}, \mathrm{Al}, \mathrm{Fe}, \mathrm{Mg}$, Ti, etc.). $\mathrm{M}-\mathrm{OH}$ sites will react to form $\mathrm{H}_{2} \mathrm{O}$ while concurrently healing the oxygen bridge defect:

$$
\mathrm{M}-\mathrm{OH}+\mathrm{M}-\mathrm{OH} \rightarrow \mathrm{M}-\mathrm{O}-\mathrm{M}+\mathrm{H}_{2} \mathrm{O}(\mathrm{g})
$$

We note that RD on the surface is not completely necessary for the production of molecular water. Recent proton irradiation and thermal annealing studies have shown molecular water to form within the irradiation layer (Zhu et al. 2020; Zeng et al. 2021). The ejection occurs at thermal velocities and is controlled by the local surface temperature. The most probable ejection velocity at $300 \mathrm{~K}$ is $610 \mathrm{~m} \mathrm{~s}^{-1}$. (For comparison, the escape velocity of the Moon is $2.4 \mathrm{~km} / \mathrm{s}$.) The porosity and fractal nature of the regolith might affect the ejection angles and velocities.

If a trapped $\mathrm{H}$-atom is present, it can possibly react with a $\mathrm{M}-\mathrm{OH}$ site forming $\mathrm{H}_{2}$. The

$$
\mathrm{M}-\mathrm{OH}+\mathrm{M} \cdots \mathrm{H} \rightarrow \mathrm{M}-\mathrm{O}-\mathrm{M}+\mathrm{H}_{2}(\mathrm{~g})
$$


reactions can involve both surface and sub-surface sites. However, previous experimental work has shown that formation of molecular hydrogen is only relevant near the saturation limit $\left(\sim 10^{17} \mathrm{H}^{+} \mathrm{cm}^{-2}\right.$ ) (Mattern et al. 1976; Blanford et al. 1985). In addition, molecular hydrogen was suggested to form (Starukhina 2006) via

$$
\mathrm{M}-\mathrm{OH}+\mathrm{M}-\mathrm{OH} \rightarrow \mathrm{M}-\mathrm{O}-\mathrm{O}-\mathrm{M}+\mathrm{H}_{2}(\mathrm{~g}) .
$$

However, experimental work has shown the energy barrier for formation of molecular hydrogen via terminal hydroxyl sites is considerably higher than that of water formation, resulting in nearly $100 \%$ yield of water via RD on a highly hydroxylated metal oxide surface (Du et al. 2012). While the experimental conditions are not fully representative of regolith on an airless body, the overall mechanism and the disparity of activation energies/kinetics are validated with proton irradiation studies; Crandall et al. (2019) demonstrated that only $2 \%$ of the implanted protons resulted in the formation of $\mathrm{H}_{2}$.

Alternative pathways of in situ water formation through chemical sputtering have also been identified as a possible source term for water on airless bodies (Crider and Vondrak 2000; Gibson 1977; Potter 1995). In particular, a small yield of water ions directly sputtered under $\mathrm{keV} \mathrm{D}^{+}$bombardment from the surface of oligoclase was measured at $10^{-4} \mathrm{D}_{2} \mathrm{O}^{+}$ per incident $\mathrm{D}^{+}$(Blanford et al. 1985) and $10^{-4} \mathrm{D}_{2} \mathrm{O}^{+}$per incident $\mathrm{D}^{+}$from the surface of $\mathrm{SiO}_{2}$ (Managadze et al. 2011). Similarly, water formation was observed from reactions of hydrogen atoms with an oxide layer of stainless steel (Ishibe and Oyama 1979).

In summary, proton implantation into any airless body composed of regolith enriched in minerals of various metal oxides will result in the formation of bound hydroxyls. Upon heating, this results in the formation of molecular hydrogen, and water (Fig. 1). The rate of each is controlled by the local surface temperature, concentration profiles, and the associated activation energies. Since RD and chemical sputtering both require the solar wind, they can be considered solar wind water formation processes.

Typically, the temperature required for complete conversion of the implanted $\mathrm{OH}$ via RD is much greater than the highest temperature reached on the lunar surface. For example, the water formation rate via $\mathrm{RD}$ from $\mathrm{SiO}_{2}$ peaks at $\sim 600 \mathrm{~K}$ (Gun'ko et al. 1998). However, other metal oxides have significantly lower peak $\mathrm{RD}$ temperatures, e.g., $\mathrm{TiO}_{2}$ is $\sim 250 \mathrm{~K}$ (Henderson 1994), $\mathrm{MgO}$ is $225 \mathrm{~K}$ (Stirniman et al. 1996), and $\mathrm{Al}_{2} \mathrm{O}_{3}$ is $\sim 350 \mathrm{~K}$ (Nelson et al. 1998). In addition, time is on the side of water formation on these airless bodies as they often exhibit long diurnal cycles. Consequently, despite the slow reaction rate at 300-400 K, the amount of time the regolith experiences dayside temperatures compensate for the low production rate of water. While the minerals identified above do not exist in pure form in the lunar regolith, the necessary activation energies can be approximated based on the assumption that at the microscopic scale, the lunar regolith will behave in a similar fashion to their respective pure representatives, e.g., the $\mathrm{MgO}$ network in pyroxene is similar to pure $\mathrm{MgO}$.

Jones et al. (2018) demonstrated that a minor fraction $(\sim 30 \%)$ of the total sites produced by the solar wind on an Apollo mare sample (10084) were available for recombinative desorption during typical noontime temperatures on the Moon. Activation will remove some $\mathrm{OH}$ sites but not all, resulting in a latitude dependent IR signature (Jones et al. 2018) that has been observed in some interpretations of the $\mathbf{M}^{3}$ data set (McCord et al. 2011; Li and Milliken 2017; Wöhler et al. 2017b). Overall, RD on the lunar surface results in the polar regions exhibiting the highest concentration of chemically trapped hydrogen in the form of bound hydroxyls, with a latitude dependent $\mathrm{OH}$ signal and a relatively $(\Delta \mathrm{ppm}<1)$ constant $\mathrm{OH}$ signal at all longitudes. In addition, given both the high temperatures on Mercury and 
the amount of time the regolith experiences those temperatures, recombinative desorption is estimated to account for $10 \%$ of the ice on Mercury trapped in the permanently shadowed regions (Jones et al. 2020).

Water formation following a simulated micrometeoroid impact has been demonstrated in the lab as well. Zhu et al. (2019) exposed anhydrous olivine $(\mathrm{Mg}, \mathrm{Fe})_{2} \mathrm{SiO}_{4}$ samples to a $\mathrm{D}_{2}^{+}$ ion beam. (Deuterium is used instead of regular hydrogen to distinguish any resulting hydroxyl or molecular water from potential background sources.) After the ion exposure, the samples were exposed to a pulsed infrared laser, followed by temperature-programmed desorption (TPD). The pulsed laser generates intense heating events with temperatures that can reach higher than $1,400 \mathrm{~K}$, similar to temperatures produced by micrometeoroid impacts. Simulations of micrometeoroid impacts were conducted at temperatures of 10 and $300 \mathrm{~K}$. These laboratory simulation experiments demonstrated that water can be generated and released from anhydrous minerals implanted with solar-wind protons through rapid energetic heating, as would occur during micrometeoroid impacts.

In summary, water can be formed in situ by thermally induced reactions of solar wind implanted hydroxyls on grain surfaces on airless bodies. A fraction of the water formed from this mechanism is expected to accumulate in cold PSRs (Sect. 8).

\section{Observations of Hydroxyl on the Lunar Surface}

Lunar rocks are made up of minerals and glasses, with only trace amounts of water (Papike et al. 1991; Greenwood et al. 2011). Some of the hydrogen identified in Apollo samples is indigenous (Saal et al. 2008; Boyce et al. 2010). Hydroxyl found in glasses in Apollo samples has isotopic ratios indicating it is derived from solar wind, rather than from meteoroids or terrestrial contamination (Liu et al. 2012). Native $\mathrm{H}_{2} \mathrm{O}$ may be found in the amorphous rims formed on silicate grains through solar wind irradiation, as identified by Bradley et al. (2014) on interplanetary dust particles.

\subsection{Spectroscopic Observations of $\mathrm{OH} / \mathrm{H}_{2} \mathrm{O}$}

The Moon Mineralogy Mapper $\left(\mathrm{M}^{3}\right)$ was a hyperspectral imaging spectrometer onboard the Indian Chandrayaan-1 spacecraft launched in 2008 (Green et al. 2011). It measured the spectral reflectance on the lunar surface from 0.43 to $3.0 \mu \mathrm{m}$ which was split into 260 continuous spectral bands ( $\sim 10 \mathrm{~nm}$ sampling interval) (Green et al. 2011). The $\mathrm{M}^{3}$ images cover over $95 \%$ of the lunar surface. The spectral bands of $\mathrm{M}^{3}$ data near $3 \mu \mathrm{m}$ were used to assess the hydration features on the lunar surface. The fundamental stretching of $\mathrm{OH}$ and the first overtone of the molecular water vibration both occur near $3 \mu \mathrm{m}$. The absorption strength of the reflectance data near $3 \mu \mathrm{m}$ can be directly linked to the absolute $\mathrm{OH} / \mathrm{H}_{2} \mathrm{O}$ content.

Lunar surface hydroxyl or water was assessed globally through analyzing the absorption features of $\mathrm{OH}$ and $\mathrm{H}_{2} \mathrm{O}$ near $3 \mu \mathrm{m}$ seen by three different missions/instruments, namely Chandrayaan-1 Moon Mineralogy Mapper ( $\left.\mathrm{M}^{3}\right)$ (Pieters et al. 2009), EPOXI near infrared spectrometer (Sunshine et al. 2009), and Cassini Visual and Infrared Mapping Spectrometer (VIMS) (Clark 2009). Both $\mathrm{M}^{3}$ and EPOXI data (280 m/pixel and $60 \mathrm{~km} /$ pixel, respectively) suggest that the $3 \mu \mathrm{m}$ absorption strength shows strong latitudinal dependence from the midlatitude to the poles and no pronounced absorptions near $3 \mu \mathrm{m}$ were seen near the equator (Pieters et al. 2009; Sunshine et al. 2009). It might be due to the much lower spatial resolution of the VIMS data ( $175 \mathrm{~km} /$ pixel) that the $\mathrm{OH} / \mathrm{H}_{2} \mathrm{O}$ absorptions near $3 \mu \mathrm{m}$ exhibit only 


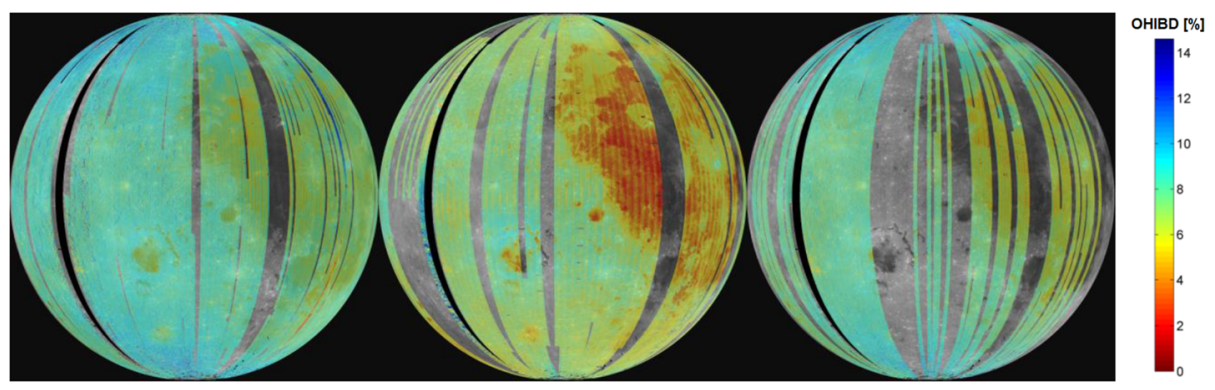

Fig. 2 Depth of the 3- $\mu \mathrm{m}$ absorption band (OHIBD) inferred from $\mathrm{M}^{3}$ data and overlaid on $\mathrm{M}^{3} 1.579 \mu \mathrm{m}$ reflectance. In the morning (left), the OHIBD slightly increases from the equator toward the poles. At midday (middle), the OHIBD decreases globally and does not show a dependence on latitude. In the afternoon (right), the OHIBD increases globally and shows a dependence on latitude similar to the morning. At all times of day, the OHIBD is higher in the highlands than in the maria. Image reproduced with permission from Grumpe et al. (2019)

weak latitudinal variation. The estimates of total $\mathrm{OH} / \mathrm{H}_{2} \mathrm{O}$ content from the three datasets at the strongest $3 \mu \mathrm{m}$ absorption are consistent with each other at $\sim 1000 \mathrm{ppm}$ at the polar region (Clark 2009; Pieters et al. 2009; Sunshine et al. 2009). Diurnal variation of the $3 \mu \mathrm{m}$ absorption strength is observed in the $\mathrm{M}^{3}$ and EPOXI data (Pieters et al. 2009; Sunshine et al. 2009).

Further improved thermal correction of the $\mathrm{M}^{3}$ data also suggest that the $\mathrm{OH} / \mathrm{H}_{2} \mathrm{O}$ absorptions near $3 \mu \mathrm{m}$ show strong latitudinal variation and diurnal variation ( $\mathrm{Li}$ and Milliken 2017; Wöhler et al. 2017b). Li and Milliken (2017) performed laboratory experiments using basaltic glasses and anorthosite that are related to the lunar surface composition to link the 3 - $\mu \mathrm{m}$ absorptions strength with the absolute water group content $\left(\mathrm{OH}+\mathrm{H}_{2} \mathrm{O}\right)$. The results suggest that the absolute abundances of $\mathrm{OH} / \mathrm{H}_{2} \mathrm{O}$ at the lunar surface varies from $<20 \mathrm{ppm}$ near the equator to $\sim 1000 \mathrm{ppm}$ near the pole ( $\mathrm{Li}$ and Milliken 2017). The diurnal variation of $\mathrm{OH} / \mathrm{H}_{2} \mathrm{O}$ near the equator is very weak, which could be due to the low water content at this latitude zone. The strongest diurnal variation of $\mathrm{OH} / \mathrm{H}_{2} \mathrm{O}$ is seen in the mid latitude between $\sim 25^{\circ}-60^{\circ}$ (up to $200 \mathrm{ppm}$ ), while no obvious diurnal variation is seen at latitudes > $\sim 60^{\circ}$ at both the northern and southern hemispheres (Li and Milliken 2017). The integrated time regolith was exposed to the micrometeoroid and solar wind environment is known as "maturity" (McKay et al. 1991). A strong correlation between the maturity of lunar regolith and mapped $\mathrm{OH} / \mathrm{H}_{2} \mathrm{O}$ content is observed at the mid-high latitudes of the Moon ( $\mathrm{Li}$ and Milliken 2017). However, different approaches for correcting the thermal effect of the $\mathrm{M}^{3}$ data result in vastly different spatial and temporal variation of the $3 \mu \mathrm{m}$ absorption. Bandfield et al. (2018) developed a new method for removing the thermal emission component from the $\mathrm{M}^{3}$ reflectance spectra and found that there is no latitudinal or diurnal variation in the $3-\mu \mathrm{m}$ absorption strength.

Wöhler et al. (2017a) processed the $\mathrm{M}^{3}$ data using thermal and topographic corrections. The 3- $\mu \mathrm{m}$ band depth maps constructed by Wöhler et al. (2017a) for the southern highlatitude area around the crater Boguslawsky indicate that the $3-\mu \mathrm{m}$ band is stronger at lunar morning than at midday. Wöhler et al. (2017b) constructed nearly global $\mathrm{OH}$ integrated band depth (OHIBD) maps (Fig. 2). In the lunar morning (07:00-08:00), the 3- $\mu \mathrm{m}$ band depth in the polar highlands exceeds the value in the equatorial highlands by $20-30 \%$. The lunar maria exhibit OHIBD values lower by $10-15 \%$ than the highlands, where high-Ti mare basalt have the lowest OHIBD. At lunar midday (10:00-14:00), the dependence of the OHIBD on latitude vanishes, and the OHIBD in the equatorial highlands is 10-15\% lower than in 
the morning. All maria are associated with low OHIBD values, with the lowest OHIBD occurring in high-Ti maria. In the lunar afternoon (16:00-17:00), the OHIBD is similar to but slightly lower than in the morning. The relative OHIBD decreases by $\sim 30 \%$ between morning and midday in the polar highlands, whereas it is nonzero and nearly invariable with time of day in the low-latitude highlands. In high-Ti mare areas, much stronger timeof-day-dependent relative OHIBD variations of $\sim 50-70 \%$ can be observed. Wöhler et al. (2017b) explained these observations by the superposed effects of a time-of-day-dependent, weakly bounded $\mathrm{OH} / \mathrm{H}_{2} \mathrm{O}$ component built up by $\mathrm{H}$ adsorption from the solar wind and later removed by thermal evaporation and photolysis, plus a strongly bounded $\mathrm{OH} / \mathrm{H}_{2} \mathrm{O}$ component that is stable against thermal evaporation and photolysis.

Pieters et al. (2009), McCord et al. (2011), Li and Milliken (2017), Wöhler et al. (2017b), and Bandfield et al. (2018) each found widespread presence of surficial $\mathrm{OH} / \mathrm{H}_{2} \mathrm{O}$ based on $\mathrm{M}^{3}$ spectral reflectance data, consistent with observations made through other near-infrared spectrometers (Clark 2009; Sunshine et al. 2009; Honniball et al. 2020). McCord et al. (2011), Starukhina (2012), and Bandfield et al. (2018) concluded the diurnal variation may be an observational artifact, consistent with the hydroxyl dynamics expected from physical chemistry (Sect. 3). The degree of latitude dependence varies among authors. Recent earthbased observations by Honniball et al. (2020) also suggest that the $3 \mu \mathrm{m}$ band varies with latitude, composition, and local time of day.

The speciation ( $\mathrm{OH}$ or $\mathrm{H}_{2} \mathrm{O}$ or both) on the lunar surface is still unclear from $\mathrm{M}^{3}$ measurements. The $\mathrm{OH}$ vibration band is centered between 2.65 and $2.9 \mu \mathrm{m}$ and the fundamental stretching vibration band of $\mathrm{OH}$ near $2.8 \mu \mathrm{m}$, while the $3.0 \mu \mathrm{m}$ absorption band of $\mathrm{H}_{2} \mathrm{O}$ corresponds to the first overtone of its bending vibration. The presence of $\mathrm{H}_{2} \mathrm{O}$ makes the whole $3 \mu \mathrm{m}$ spectra broader and more symmetric, whereas $\mathrm{OH}$ exhibits an asymmetric absorption band extending well beyond $3 \mu \mathrm{m}$. However, an $\mathrm{OH}$ absorption band may also occur at wavelengths of $>2.9 \mu \mathrm{m}$, depending on the energy characterizing the binding of the hydroxyl with the respective cation; thus, a broad $\mathrm{OH}$ absorption band may well be present in the range between 2.65 and $3.5 \mu \mathrm{m}$ (e.g., Dyar et al. 2010). The wavelength range of $\mathrm{M}^{3}$ is too limited to accurately determine the full shape and maximum absorption point in the $3 \mu \mathrm{m}$ region, making it difficult to differentiate between $\mathrm{OH}$ and $\mathrm{H}_{2} \mathrm{O}$, particularly if both species are present. The EPOXI and VIMS data cover a wider spectral range, but the possible thermal residual and low spatial resolution complicate the interpretation of the $3 \mu \mathrm{m}$ band shape and make it difficult to discriminate $\mathrm{OH}$ from $\mathrm{H}_{2} \mathrm{O}$ in these two datasets. Recent observations in the 6-micron region (Honniball et al. 2021) confirm $\mathrm{H}_{2} \mathrm{O}$ is present in a sunlit region (Clavius crater) at abundances of 100-400 $\mu \mathrm{g} / \mathrm{g}$. This water may be stored in glasses, as observed in Apollo samples.

Measurements by LAMP (the Lyman Alpha Mapping Project instrument) in the far-UV also provide evidence for surface hydration on the Moon varying in abundance with both terrain type and local time (Hendrix et al. 2012, 2019). Highlands regions are more hydrated than mare regions, consistent with the results from $\mathrm{M}^{3}$. Hendrix et al. (2019) interpret the variations in the far-UV spectra as a partial monolayer of water thermally adsorbing and desorbing, but $\mathrm{OH}$ is not ruled out. When the Moon crosses the Earth's magnetotail, where the solar wind source of protons is absent, no decrease in surface hydration was observed by LAMP. Recently, Wang et al. (2021) also found that the hydration level in the polar regions remains unchanged during passage through Earth's magnetotail, based on their analysis of $\mathrm{M}^{3}$ data. 


\subsection{Local Anomalies}

Lunar swirls are bright structures uncorrelated with topography, which are associated with local magnetic fields. A commonly accepted hypothesis is that lunar swirls exist due to shielding of the surface by a preexisting magnetic field, leading to the prevention of soil maturation (e.g., Hood and Schubert 1980; Glotch et al. 2015). An alternative hypothesis is that they were induced by external processes, such as interaction with cometary gas, leading to regolith compaction and/or removal of the uppermost regolith layer (e.g., Schultz and Srnka 1980; Shevchenko 1993; Pinet et al. 2000).

Similar to previous studies (e.g., Kramer et al. 2011; Li and Milliken 2017; Li and Garrick-Bethell 2019), recent results by Hess et al. (2020) indicate a weaker 3- $\mu \mathrm{m}$ band at the swirl locations than on the surrounding surface. This finding supports the assumption that the magnetic field locally reduces the flux of solar wind protons, leading to a reduced rate of $\mathrm{OH} / \mathrm{H}_{2} \mathrm{O}$ formation in the regolith. However, Hess et al. (2020) also showed that the spectral appearance of the northeastern parts of the Reiner Gamma swirl can be better explained by regolith compaction rather than by immature soil, due to the absence of variations in spectral reddening and in the depth of the mafic absorption bands between on-swirl and off-swirl surfaces. Furthermore, they described a small swirl structure in the western part of Mare Moscoviense that is not associated with a magnetic anomaly and does not show reduced OHIBD values compared to the surrounding surface. These findings provide evidence that external processes might be relevant for the formation of swirls, such as the interaction with cometary gas, which Shevchenko (1993) compared to the effect of a landing rocket jet on the lunar regolith. This would lead to soil compaction and, according to the model by Hapke (2008), increased surface albedo without changing the mafic band depths and spectral slope. Additionally, the cometary gas may also remove the uppermost, highly matured regolith layer and reveal immature material, which would be consistent with the observation by Hess et al. (2020) that spectra indicating a low surface maturity occur at all studied swirls. Using spectra of the lunar surface acquired by the Yutu rover at different distances from the Chang'E-3 lander, Wu and Hapke (2018) demonstrated that a landing rocket jet causes exactly this effect. These considerations suggest that the magnetic field appears to be relevant for extending the lifetime of the swirls by keeping their surfaces immature and bright, rather than for their actual formation.

$\mathrm{M}^{3}$ data also provided evidence of lunar interior water. An enhanced hydration feature was observed in the central peak of Bullialdus crater and such hydration anomalies were attributed to the lunar interior origin (Klima et al. 2013). Excessive water group signature is observed in almost all large pyroclastic deposits near the equatorial regions, where the $\mathbf{M}^{3}$ data were acquired under low phase angles and are thus more reliable, which is consistent with an endogenous origin (Milliken and Li 2017). Analysis results from Milliken and Li (2017) also suggest that high-Ti pyroclastic deposits show higher water content than lowTi ones, indicating either different water contents in magma sources, different degassing history, or both.

\section{Observations of the Water Group in the Lunar Exosphere}

During the Apollo missions, several exospheric species were identified by the LACE mass spectrometer, such as $\mathrm{He}, \mathrm{Ar}$, and $\mathrm{CH}_{4}$. The Apollo 14 Suprathermal Ion Detector Experiment (SIDE) detected ions of mass $18 \mathrm{amu} / \mathrm{q}$ during an event of approximately 14 hours duration (Freeman et al. 1973). Freeman and Hills (1991) concluded that the most probable 


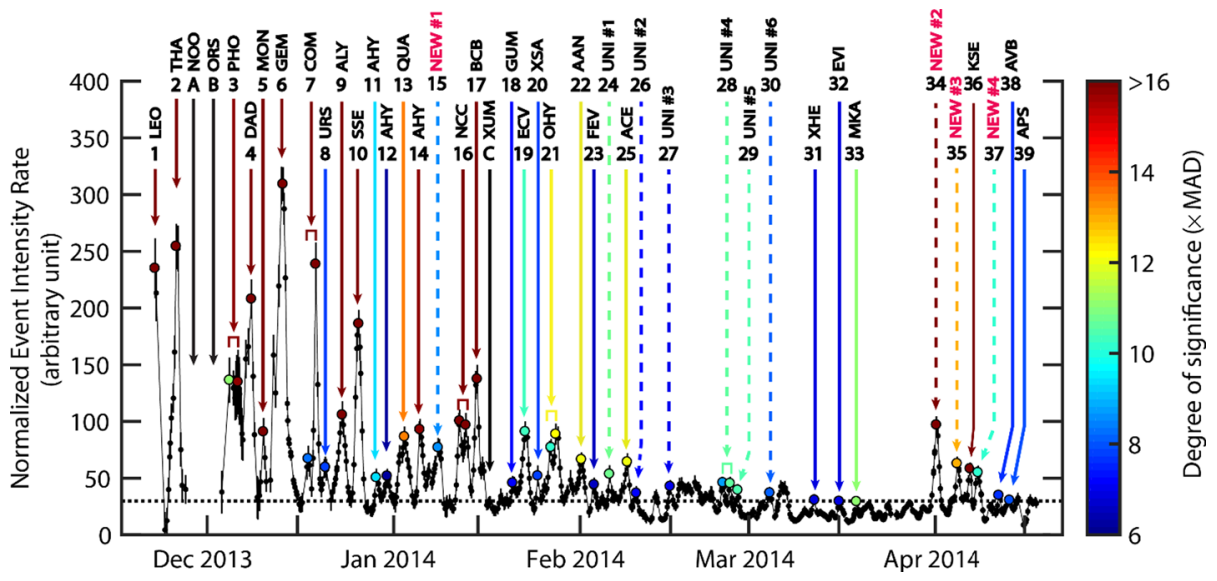

Fig. 3 Identification of sporadic water group events linked to meteoroid streams in the NMS data. The data reveals atypical peaks (data points colored based on their statistical significance) with statistical significance $>6 \times$ Median Absolute Deviation (MAD). Solid arrows denote the timing of established streams. Six dashed arrows (labeled "UNI") do not correspond to any established streams. Streams \#15, 34, 35, and 37 (labeled "NEW") are believed to correspond to new streams. Stream groups A and B occurred while NMS was not operational. Established stream $\mathrm{C}$ was undetected. The dotted line reflects the median observed intensity. The uncertainty error bars (black) reflect $3 \sigma$ due to counting statistics and data processing. Image reproduced with permission from Benna et al. (2019)

source of these water ions was the Lunar Module (Stern 1999). CHACE (Chandra's Altitudinal Composition Explorer) was a mass spectrometer on the Moon Impact Probe (MIP), which was released from Chandrayaan-1 on November 18, 2008. Based on measurements by CHACE, Sridharan et al. $(2010,2015)$ inferred $\mathrm{H}_{2} \mathrm{O}$ densities on the order of $10^{6} \mathrm{~cm}^{-3}$, which far exceeds the upper limit measured later by LADEE, and this interpretation of the data is not widely accepted.

Over the course of its relatively short mission (8 months), the LADEE spacecraft collected measurements of the composition of the lunar exosphere using the Neutral Mass Spectrometer (NMS) instrument. While other key volatiles were rapidly identified (Benna et al. 2015a; Hodges 2016), initial data analyses did not yield direct detection of water group species. An upper limit density for $\mathrm{H}_{2} \mathrm{O}$ of $9 \mathrm{~cm}^{-3}$ at $4 \mathrm{~km}$ altitude above the sunrise terminator was established based on the observed average instrument background (Benna et al. 2015b).

Subsequent analyses revealed that small changes in the instrument's water background captured faint variations in water released into the exosphere, well below what could be detected by direct (instantaneous) observations. These new observations revealed that water fluctuates in the lunar exosphere between a background level of $0.6 \mathrm{~cm}^{-3}$ and peak densities of $\sim 40 \mathrm{~cm}^{-3}$. The temporal variation of $\mathrm{OH} / \mathrm{H}_{2} \mathrm{O}$ is dominated by episodic and short-lived intense events (Fig. 3). These high-intensity events are predominant in the period between November and January during which the Moon encounters a series of well-known, annually occurring, strong meteoroid streams (e.g., Leonids, Geminids, and Quadrantids). Benna et al. (2019) demonstrated that these events captured the signatures of water releases into the lunar exosphere by meteoroid strikes on the lunar surface. The NMS instrument cannot resolve whether the parent exospheric molecule of the measured water is $\mathrm{H}_{2} \mathrm{O}$ or OH. Incident hydroxyl radicals would be rapidly converted to $\mathrm{H}_{2} \mathrm{O}$ by reaction with atomic hydrogen on the instrument internal surfaces. 


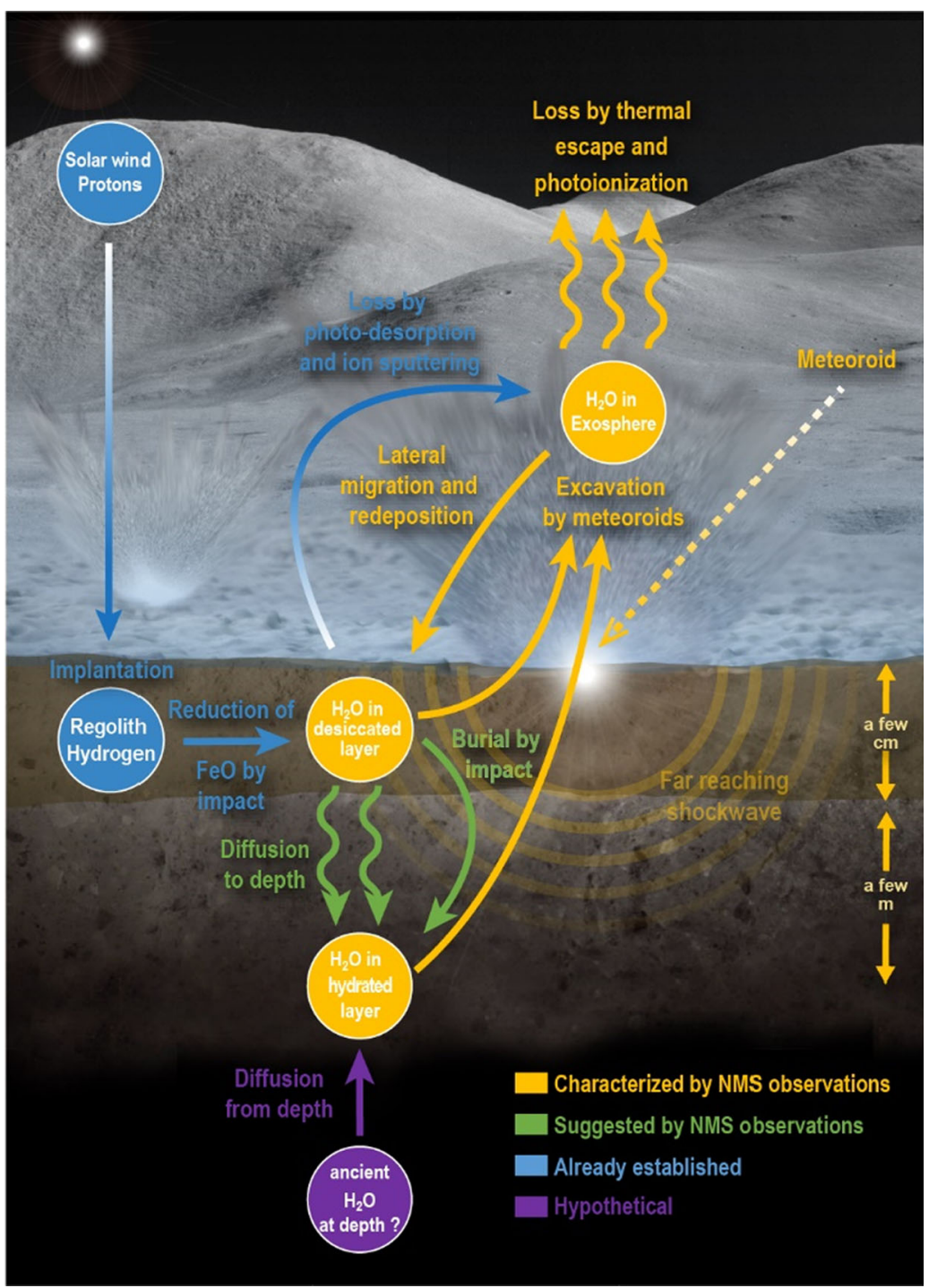

Fig. 4 The lunar water cycle as suggested by the NMS observations. Solar wind-implanted hydrogen is the main exogenous source of water production. Synthesized water is extracted by the far-reaching shock waves generated by large micrometeoroids that strike the surface. The liberated water escapes or is redeposited elsewhere. In order to sustain the water loss from meteoroid impacts, the hydrated soil might require replenishment from a deeper ancient water reservoir. Image reproduced with permission from Benna et al. (2019)

A comparison of the NMS measurements with those of the Lunar Dust EXperiment (LDEX) and an exosphere model shows that the mass flux of released $\mathrm{OH} / \mathrm{H}_{2} \mathrm{O}$ is largely generated by meteoroids in the $0.15 \mathrm{~g}-10^{6} \mathrm{~g}$ mass range, with smaller meteoroids having minimal contribution to the water group exosphere (Benna et al. 2019). The lack of efficiency of smaller impactors was attributed to the presence of a few-centimeter thick desiccated top layer that shielded hydrated regolith below. Only meteoroids larger than $0.15 \mathrm{~g}$ are able to pierce this dry stratum and excavate deeper soils. The hydration of the regolith 
at depth was estimated to be $220-520$ ppm by weight of $\mathrm{H}_{2} \mathrm{O}$-equivalent based on the intensity of the observed water events.

While the presence of a desiccated top layer is expected based on the spectral observations of the lunar equatorial region (Li and Milliken 2017), the NMS measurements showed that its thickness extends beyond the top millimeter of the soil. The derived thickness of the desiccated regolith layer is commensurate with the depth at which diurnal equatorial temperature swings are $220-255 \mathrm{~K}$. This implies that $\mathrm{OH} / \mathrm{H}_{2} \mathrm{O}$ has a short lifetime within the surface thermally active layer because it is rapidly transported by thermal desorption and diffusion upward to the surface, where it can be lost, or downward deeper in the soil where it can be sequestered.

The NMS observations also reveal that, in order to account for the relatively large intensities of the detected events, impacts must yield an amount of water 5-13 times the impactor mass. Therefore, the released water cannot originate from structural water in hydrous minerals, which requires high shock pressures in order to devolatilize as part of melts and vapors. Instead, it most likely comes from water desorbed from regolith grains by the shock wave that expands across the impact site, well beyond the confines of the volume of the excavated crater (Fig. 4).

If the regolith has a specific surface area of $0.5 \mathrm{~m}^{2} \mathrm{~g}^{-1}$ and a density of $1.7 \mathrm{~g} \mathrm{~cm}^{-3}$ at $10 \mathrm{~cm}$ (Vasavada et al. 2012), then the maximum amount of adsorbed water would be $\sim 150$ ppm using the standard definition of a saturated monolayer $\left(1 \times 10^{19}\right.$ molecules $\left.\mathrm{m}^{-2}\right)$. However, the temperature of the lunar regolith at $8 \mathrm{~cm}$ depth still reaches $260 \mathrm{~K}$ over a diurnal cycle (Vasavada et al. 2012). Temperature programmed desorption measurements (Poston et al. 2015; Jones et al. 2020) have shown that regolith does not contain enough high energy binding sites to adsorb water at these temperatures. RD following a meteoroid impact into the solar wind implanted regolith can potentially explain the LADEE observations.

By aggregating all NMS observations, Benna et al. (2019) estimated that the water loss rate due to meteoroid impact is $3.4-8.1 \mathrm{~g} \mathrm{~s}^{-1}$, which is larger than estimates of water synthesis rate by solar wind (Housley et al. 1973; Arnold 1979). The balance between solar wind production and loss by micrometeoroids would imply that the Moon is in a net water loss regime.

\section{Observations of Surface Reservoirs and an Exosphere on Ceres}

\subsection{Ice Reservoirs}

(1) Ceres is the largest of the asteroids, with diameters of $964 \times 964 \times 892 \mathrm{~km}$ and a rotation period of $9.07 \mathrm{~h}$. It is situated in the middle asteroid belt, $2.77 \mathrm{AU}$ from the sun. Ceres has an effective temperature of $166 \mathrm{~K}$ and a subsolar temperature of $235 \mathrm{~K}$. Its low density of $2.16 \mathrm{~g} / \mathrm{cm}^{3}$ reveals that water ice is a major constituent, as silicates and iron have a much higher density and the bulk porosity of such a large body could not be large. It also has hydrated minerals, consistent with extensive aqueous alteration during its early history, and spectrally it is a dark, carbonaceous asteroid (McSween et al. 2017). Due to its "roundness", presumably caused by topographic compensation during its early history of radiogenic heating, Ceres is also classified as a dwarf planet.

As an ice-rich body, Ceres has a steady supply of water that can feed an exosphere. For this reason, Ceres must have a water exosphere, the remaining question being how tenuous. With an escape velocity of $0.51 \mathrm{~km} / \mathrm{s}$, many species are gravitationally bound at thermal speeds. 
Thanks to the Dawn spacecraft, which orbited Ceres 2015-2018, our knowledge of Ceres has expanded dramatically. The Gamma-Ray and Neutron Detector (GRaND, Prettyman et al. 2011) measured the hydrogen concentration within the top $\sim 1 \mathrm{~m}$ of the surface (Prettyman et al. 2017). The non-icy portion of Ceres' carbon-bearing regolith contains similar amounts of hydrogen as those present in aqueously altered carbonaceous chondrites. At moderate and high latitudes, the regolith contains high concentrations of hydrogen, consistent with broad expanses of water ice. The latitudinal dependence of the hydrogen concentration is far stronger than the longitudinal dependence, suggesting that the ice content is temperature driven, with no ice within the sensing depth of GRaND at the relatively warm equatorial regions and ice very near the surface in the cold polar regions. Fanale and Salvail (1989) had long predicted an ice table at shallow and latitude-dependent depths. Remarkably, ice has survived at shallow depths over billions of years, despite continuous sublimation and impact bombardment. Based on thermal inertia measurements, Ceres is covered by a dust mantle (Rivkin et al. 2011). Small grain sizes can act as a strong barrier to vapor diffusion, and quantitative estimates place the grain size at one micron to be consistent with the low rate of vapor diffusion (Prettyman et al. 2017; Li et al. 2019). The GRaND measurements, combined with models, suggest that the equatorial regions are ice-free to at least $1 \mathrm{~m}$ depth whereas the polar regions may have ice even at $\mathrm{cm}$ depth (Schorghofer 2016; Prettyman et al. 2017; Landis et al. 2017, 2019).

The shallow depth of ice suggests that Ceres has lost ice to space only slowly, and on a long-term average the supply to the exosphere is therefore small. If loss is by sublimation only, then the ice table corresponds to a current outgassing rate of only $0.003 \mathrm{~kg} / \mathrm{s}$, but excavation of deeper ice by impacts and ice delivered by impactors also contribute to the water exosphere.

In stark contrast to the shallow subsurface, very little ice is exposed on the surface. The large relatively bright spots seen on the surface of Ceres consist mostly of salts. Water ice was detected spectroscopically by Dawn only at a handful of locations (Combe et al. 2016, 2019; Sizemore et al. 2019), and these occurrences are at fresh craters near rim shadows and sometimes associated with landslides. Landis et al. (2019) estimated the number of iceexposing impacts, and found that impact craters that remain bright (exposed to the surface) could supply $0.08-0.56 \mathrm{~kg} / \mathrm{s}$ of water vapor on a time average.

With an axis tilt of only $4^{\circ}$ relative to the normal of the orbital plane, Ceres has perennially shadowed craters in its polar regions (Hayne and Aharonson 2015, Schorghofer et al. 2016). Within some of these PSRs, bright deposits have been identified that most likely consist of water ice (Platz et al. 2016). This topic will be further reviewed in Sect. 8 .

\subsection{Observations of an Exosphere (or Lack Thereof)}

Numerous attempts have been made to detect an exosphere around Ceres with earth-based and space telescopes (Table 2). Most of these observations resulted in no detection, but the upper bounds that could be obtained were often very high. Two sets of telescopic observations resulted in positive detections. A'Hearn and Feldman (1992) observed escaping OH. If this $\mathrm{OH}$ formed by photodissociation of $\mathrm{H}_{2} \mathrm{O}$, the $\mathrm{H}_{2} \mathrm{O}$ production rate is roughly $10^{26} \mathrm{~s}^{-1}$. With the Herschel Space Observatory, Küppers et al. (2014) detected $\mathrm{H}_{2} \mathrm{O}$ three out of four times. Combined with modeling they estimate the outgassing rate to be $2 \times 10^{26} \mathrm{~s}^{-1}(6 \mathrm{~kg} / \mathrm{s})$. The last observation listed in Table 2 was carried out when Ceres was near perihelion, when any sublimation driven activity can be expected to be enhanced, but no gaseous $\mathrm{OH}$ was detected within the sensitivity of the measurement.

The Dawn spacecraft found no direct evidence for an exosphere around Ceres, nor did it carry an instrument designed for that purpose. Reports of a haze (Nathues et al. 2015; 
Table 2 List of searches for an atmosphere around Ceres. See text for further description

\begin{tabular}{llll}
\hline Authors & Instrument & Species & Abundance $\left(\mathrm{s}^{-1}\right)$ \\
\hline A'Hearn and Feldman (1992) & Int. UV Explorer & $\mathrm{OH}$ & {$\left[\mathrm{H}_{2} \mathrm{O}\right] \approx 10^{26}$} \\
Rousselot et al. (2011) & Very Large Telescope & $\mathrm{OH}$ & {$[\mathrm{OH}]<7 \times 10^{25}$} \\
Küppers et al. (2014) & Herschel Space Observatory & $\mathrm{H}_{2} \mathrm{O}$ & {$\left[\mathrm{H}_{2} \mathrm{O}\right] \approx 10^{26}$} \\
Roth et al. (2016) & Hubble Space Telescope & $\mathrm{O}$ & {$\left[\mathrm{H}_{2} \mathrm{O}\right]<4 \times 10^{26}$} \\
Jia et al. (2017) & Dawn GRaND & $($ electrons) & {$\left[\mathrm{H}_{2} \mathrm{O}\right] \approx 6 \times 10^{25}(?)$} \\
McKay et al. (2017) & Apache Point Observatory & $\mathrm{O}$ & {$\left[\mathrm{H}_{2} \mathrm{O}\right]<5 \times 10^{28}$} \\
Roth (2018) & Hubble Space Telescope & $\mathrm{H}, \mathrm{O}, \mathrm{S}$ & {$\left[\mathrm{H}_{2} \mathrm{O}\right]<4 \times 10^{26}$} \\
Rousselot et al. (2019) & Very Large Telescope & $\mathrm{OH}$ & {$\left[\mathrm{H}_{2} \mathrm{O}\right]<2 \times 10^{26}$} \\
\hline
\end{tabular}

Thangjam et al. 2016) were quickly attributed to measurement uncertainties (Schröder et al. 2017). There were however mysterious electron bursts on three consecutive orbits (Russell et al. 2016). One of several possible explanations for such events would be a bow shock from the interaction of a solar energetic particle (SEP) event with an atmosphere. Jia et al. (2017) modeled such a situation, finding that about $6 \times 10^{25} \mathrm{~s}^{-1}(2 \mathrm{~kg} / \mathrm{s})$ water vapor production would be required to form such a shock.

Villarreal et al. (2017) found a correlation between detections of an exosphere and the inferred presence of solar energetic protons (SEP) at Ceres. Overall, the observations suggest that a transient exosphere, or even atmosphere, may appear sporadically on Ceres, but the intensity, frequency, and cause of such events are uncertain.

\subsection{Exosphere Models of Ceres}

On Ceres, the thermal speed of water molecules is comparable to the escape speed, and there is significant gravitational fallback. An exosphere or atmosphere around Ceres has a gravitational scale height (a few hundred $\mathrm{km}$ ) much smaller than the Hill radius. This situation contrasts with comets, where molecules radially stream away from the body. The Cerean exosphere has been modeled with several different types of numerical models, often with disparate results.

Tu et al. (2014) and Schorghofer et al. (2016, 2017a) modelled the exosphere as an ensemble of ballistic trajectories, assuming the molecules thermally accommodate when in contact with the surface. This yields a half-life of the water exosphere of about $7 \mathrm{hr}$. On average, a water molecule undergoes 3 ballistic hops before it is lost by gravitational escape. These authors also quantified the delivery of water molecules to PSRs, demonstrating that a sizable fraction of outgassed water will end up in cold traps.

In connection with the Herschel Space Observatory observations, Küppers et al. (2014) simulated a collisional atmosphere with a Direct Simulation Monte Carlo (DSMC) model, which resulted in an outgassing rate of $6 \mathrm{~kg} / \mathrm{s}$. Formisano et al. (2016) used a comet Single Particle Hydrodynamics model for a vapor-dust mixture, and predicted that an optically thin atmosphere could be maintained for tens of days after an outgassing event.

Fanale and Salvail (1989) and Hayne and Aharonson (2015) explored the possibility that Ceres might have polar water ice caps, and concluded that, with realistic parameters, no polar ice caps are to be expected, consistent with the subsequent observations by the Dawn spacecraft. However, Ceres may have optically thin seasonal caps. Molecular residence times at polar temperatures are long enough to allow the seasonal buildup of water 
Fig. 5 Ballistic hops of water molecules according to model calculations. On Mercury and the Moon, water molecules are eventually lost due to photo-destruction; on Ceres most are lost through gravitational escape. Image reproduced with permission from Schorghofer et al. (2017a)

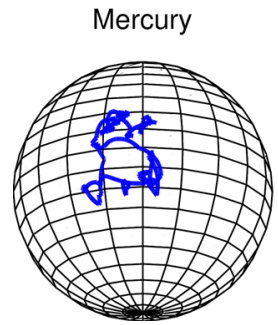

The Moon

Ceres
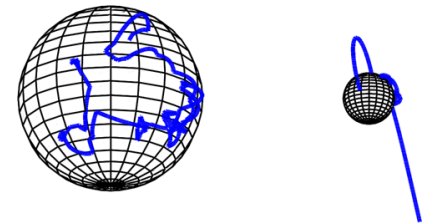

molecules delivered by the exosphere even beyond polar winter (Schorghofer et al. 2017a). This seasonal water reservoir is, at this point, purely a theoretical prediction.

\section{Lateral Transport in the Water Exosphere}

The lateral transport of water molecules on nominally airless bodies is hypothesized to occur through ballistic hops, punctuated by encounters with the planetary surface (e.g., Watson et al. 1961a,b; Butler 1997).

How water group molecules interact with planetary regoliths remains a subject of active investigation, and a source of significant uncertainty in numerical simulations of water transport. Molecules encountering a planetary surface may be scattered or adsorbed to the surface. Adsorption can take several forms: molecules may be held by van der Waals forces (physisorption), chemically bound (chemisorption) or break apart (dissociative adsorption). The residence time of a molecule on the surface is sensitive to both surface temperature and composition. Laboratory results (e.g., Poston et al. 2015) indicate that surface residence times of water molecules can be characterized by a distribution of desorption activation energies, but in situ activation energies remain to be definitively determined (e.g., Hendrix et al. 2019).

Most volatile transport models assume that molecules fully accommodate to the local surface temperature such that upon desorption, molecular velocities may be drawn from a distribution characteristic of that temperature. Two different velocity distributions for molecules released from a surface commonly appear in the literature: (i) the Maxwell-Boltzmann distribution of velocities for a gas in thermal equilibrium, and (ii) the Maxwell-Boltzmann flux distribution for velocities of molecules crossing a surface (e.g., Brinkmann 1970). From a volatile transport perspective, both approaches appear to yield very similar results (Butler 1997; Schorghofer et al. 2017a). Figure 5 illustrates the repeated ballistic hops of water molecules on Mercury, the Moon, and Ceres according to these models. The average hop distances and hop durations of $\mathrm{H}_{2} \mathrm{O}$ molecules launched on the dayside at thermal speeds are about $150 \mathrm{~km}$ (4 minutes) on Mercury, $200 \mathrm{~km}$ (7 minutes) on the Moon (Schorghofer 2015), and on the order of the body diameter (one hour) on Ceres.

The primary loss mechanisms that act on a migrating water vapor exosphere are photodestruction and gravitational escape. On the Moon and Mercury, photolysis is the dominant loss process. Solar ultraviolet radiation can break apart water molecules into a variety of neutral and charged species, with the primary reaction being dissociation of $\mathrm{H}_{2} \mathrm{O}$ into $\mathrm{H}$ and $\mathrm{OH}$ (Huebner and Mukherjee 2015). The excess energy of dissociation imparts mean velocities of $\sim 1 \mathrm{~km} / \mathrm{s}$ and $\sim 18 \mathrm{~km} / \mathrm{s}$ to $\mathrm{OH}$ and $\mathrm{H}$, respectively (Crovisier 1989).

Barring losses to photolysis or surface processes, lateral migration of water molecules continues until a molecule reaches cold traps where surface temperature is sufficiently low that water ice may remain stable over geological timescales, unless otherwise mobilized 
by impact vaporization or plasma sputtering (Farrell et al. 2019). The fraction of water molecules delivered to a planetary surface that are ultimately cold-trapped depends on the size (gravity) and proximity of the body to the Sun, and the areal coverage of cold traps. On the Moon $\sim 10 \%$ of all water delivered to the surface by various sources is predicted to reach polar cold traps through lateral transport in the exosphere (e.g., Schorghofer 2014). When a comet impact creates a dense atmosphere, between $\sim 20 \%$ to nearly $100 \%$ of impactdelivered water that remains gravitationally bound is predicted to reach cold traps at the poles (Berezhnoi and Klumov 1998; Stewart et al. 2011; Prem et al. 2015). In contrast, Ceres' low gravity and Mercury's proximity to the Sun are anticipated to result in less efficient exospheric transport of water to cold traps (Butler 1997; Schorghofer et al. 2017a).

The structure of a water vapor exosphere on the Moon may initially reflect the nature of an episodic source (e.g., Goldstein et al. 2001), but soon approaches a quasi-steady state, characterized by an enhancement of exospheric and surface water at the dawn terminator. On many airless bodies, but particularly the Moon and Mercury, surface temperature rises rapidly at sunrise, causing adsorbed water molecules to desorb. Some of this newly mobilized water falls back to the night side of the dawn terminator while the remainder moves towards the day side, causing the surficial and exospheric enhancements that are seen in model calculations (Schorghofer et al. 2017b; Prem et al. 2018).

It is important to note that steady-state exospheres of molecular water have not yet been observed to exist on the Moon, Mercury, or Ceres, and the behavior described above is currently a model-based prediction rather than an observational fact. (The detection by LADEE could be due to $\mathrm{OH}$ or $\mathrm{H}_{2} \mathrm{O}$; those detected on Ceres are sporadic outbursts, see Sects. 5 and 6). Model results also suggest that diurnal variations in surface concentration and exospheric density may be more pronounced at higher latitudes (Sect. 4). Besides diurnal variability, seasonal trends in the lateral transport of water vapor on the Moon have also been recently examined; model results indicate that the cold traps in the northern hemisphere may accumulate more water per unit area than those in the southern hemisphere (Kloos et al. 2019).

As water is photodestroyed and cold-trapped, the mass of a water vapor exosphere decays over time. The photo-dissociation timescale 1 au from the sun is 22 hours at normal solar activity (Crovisier 1989). The decay of the total mass of the exosphere is slower than that due to hiding of water molecules on the night side (or even in topographic shadows of the daytime polar regions). This introduces the length of the solar day as a relevant time scale (Berezhnoy et al. 2003; Prem et al. 2018; Schorghofer et al. 2017b).

Exosphere models have addressed whether collisionless transport can distribute water unevenly between relatively nearby cold traps. Moores (2016) predicted that cold traps farther from the pole accumulate far more water per unit area, while others find the variations to be small (Schorghofer 2014; Prem et al. 2018). An updated version of Moores' model (Kloos et al. 2019) also predicts nearly uniform infall in the polar region, leading to a consensus among models. Cold traps are too small to have any "rain shadow" effect. The average hop distance at lunar dayside temperatures is about $200 \mathrm{~km}$; for comparison the diameter of Shoemaker Crater is $51 \mathrm{~km}$.

Although exospheric models agree in many respects, there are some current points of disagreement. One question that remains to be definitively addressed is the nature of the interaction between water molecules and pristine and radiation damaged grain surfaces. Watson et al. (1961a,b) envisioned that water molecules thermally accommodate when in contact with the surface. Hodges $(1991,2002)$ argues that water molecules will be chemisorbed instead, preventing them from leaving the surface until released by a more energetic event, such as sputtering or meteoroid impacts. That would effectively shut down 
lateral transport by the exosphere. Long-term exospheric monitoring by orbital and surface instrumentation could contribute to addressing this question (e.g., Prem et al. 2020). Another partially unresolved question is the significance of isotopic fractionation during the transport of water. Current models for the Moon agree that $\mathrm{D} / \mathrm{H}$ fractionation during transport is likely to be small, but differ on whether cold traps may be enriched (Crider and Vondrak 2000) or depleted (Schorghofer 2014) in deuterated water. Our understanding of these aspects of volatile transport will likely advance as models continue to leverage experimental and observational data.

Water molecules can also migrate into the porous subsurface, by hopping between grain surfaces. In this sense, the exosphere extends into the subsurface. This process has not been fully explored with models, but under some temperature conditions, subsurface diffusion can lead to the sequestration of ice outside of cold traps (Schorghofer and Taylor 2007; Schorghofer and Aharonson 2014).

\section{Cold Traps and Permanently Shadowed Regions}

\subsection{Temperature and Volatile Stability}

Cold traps are special regions on airless bodies where volatiles such as water ice can be stable (Urey 1952; Watson et al. 1961a,b; Arnold 1979). Many cold traps are transient, such as the night side surfaces of slow-rotating airless bodies that are cold enough only for part of the diurnal cycle before temperatures rise and volatiles mobilize. On the other end of the spectrum, some cold traps exist for billions of years in permanent shadow and contain temperatures low enough to trap water ice on these geologic time scales. Here we discuss cold traps capable of sequestering volatiles on Mercury, the Moon, and Ceres.

Low obliquity of the spin axis relative to the ecliptic is a critical component of producing stable cold traps. Without low obliquity, the spin axis will periodically orient in the direction of the sun, warm, and devolatilize cold traps.

Sunlit surfaces on Mercury and the Moon are too warm for water ice to be stable. On these bodies there can be no "ice caps." Therefore, topographic relief, often in the form of impact craters, is the critical second component for stable cold traps. Even shallow craters provide sufficient relief to create regions where the sun does not rise above the local horizon (Vasavada et al. 1999). Scattered visible light and emitted infrared radiation from illuminated surfaces near cold traps contribute to the surface energy balance in shadowed regions. For a bowl-shaped crater the equilibrium temperature of the shadowed region can be calculated analytically (Buhl et al. 1968; Ingersoll et al. 1992); the lower the depth-to-diameter ratio, the colder the shadowed surface. Diviner on LRO has mapped the temperatures on the lunar surface in detail. Figure 6 shows maximum surface temperatures in the south polar region near summer and winter solstice.

Efforts to evaluate the sublimation rates of volatiles under vacuum (e.g., Watson et al. 1961b; Vasavada et al. 1999; Zhang and Paige 2009) differ in detail but agree that at temperatures below about $110 \mathrm{~K}$, water ice will sublimate slowly enough to be stable on geologic timescales. At $110 \mathrm{~K}$, the sublimation rate is about $10 \mathrm{~cm} / \mathrm{Gyr}$. Some volatiles, such as $\mathrm{Hg}$ and $\mathrm{S}$ are less volatile than water ice and thus can be cold trapped at higher temperatures (Watson et al. 1961b). Other volatiles, such as $\mathrm{CO}_{2}$ and $\mathrm{NH}_{3}$, are more volatile than water ice ("supervolatiles") and require cold traps with temperatures below $54 \mathrm{~K}$ and $66 \mathrm{~K}$ respectively (Zhang and Paige 2009; Fig. 7). A loss rate of $1 \mathrm{~m} / \mathrm{Gyr}$ corresponds to $1 \mathrm{~nm}$ (about 3 


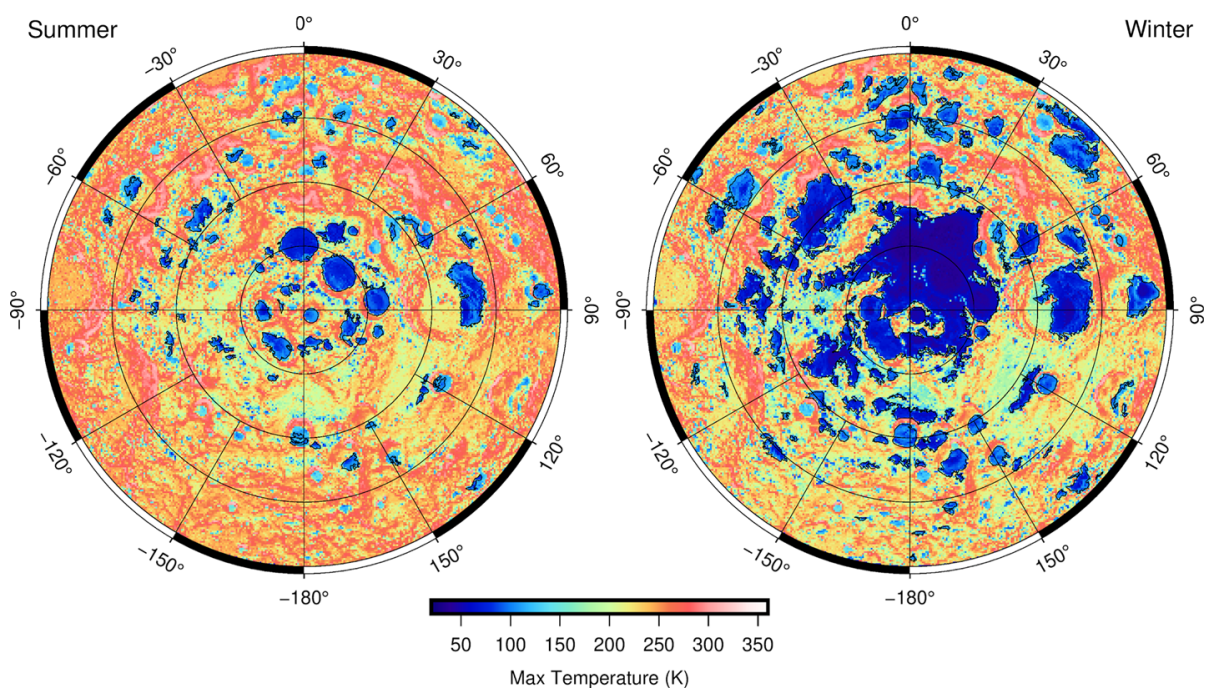

Fig. 6 Summer and winter surface temperatures in the south polar region of the Moon based on Diviner temperature measurements. The maximum is taken with respect to local time, and the data were divided into six seasonal bins for the draconic year, as in Schorghofer and Williams (2020). Shown is the region poleward of $80^{\circ} \mathrm{S}$ latitude, with black contours for $110 \mathrm{~K}$, the approximate threshold value for cold traps

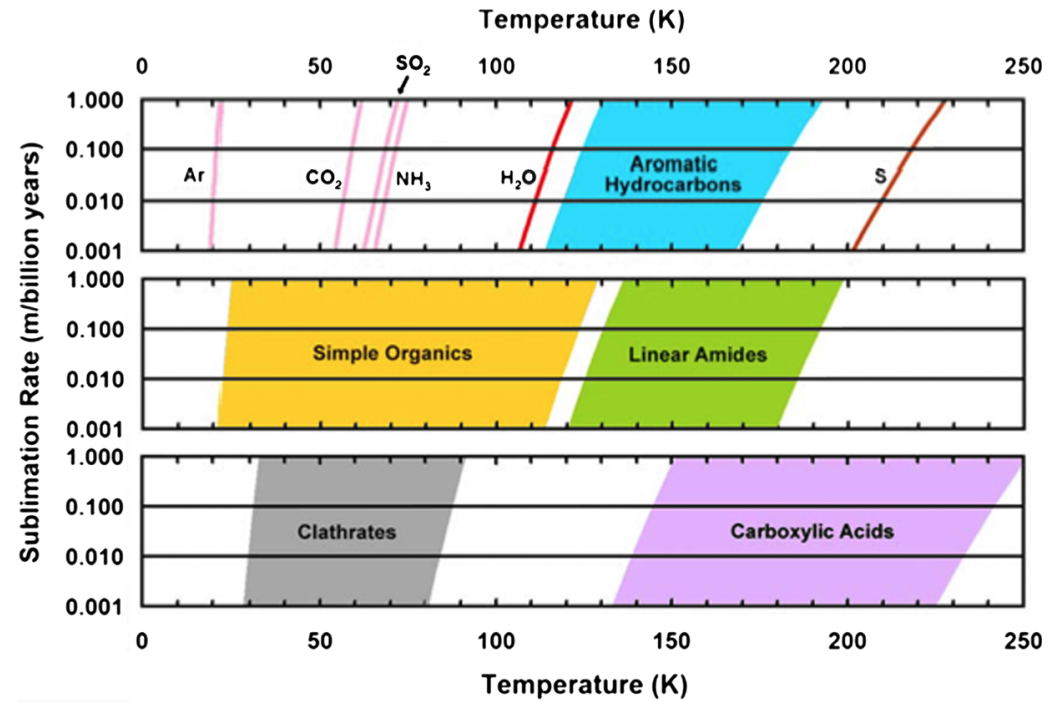

Fig. 7 Vacuum sublimation rates as a function of temperature for various organic and inorganic compounds. Except for sulfur, the volatility of common inorganic compounds is lower than that of water. Image reproduced with permission from Zhang and Paige (2009)

monolayers of $\mathrm{H}_{2} \mathrm{O}$ ) per year. Hence, water molecules might still move around even though the macroscopic loss rate is negligible.

Ice exposed on the surface is lost not only by sublimation, but also by Lyman- $\alpha$ (UV) radiation from the very local interstellar medium (Morgan and Shemansky 1991) and by sputtering from solar wind directly or from the tail of Earth's magnetosphere (Arnold 

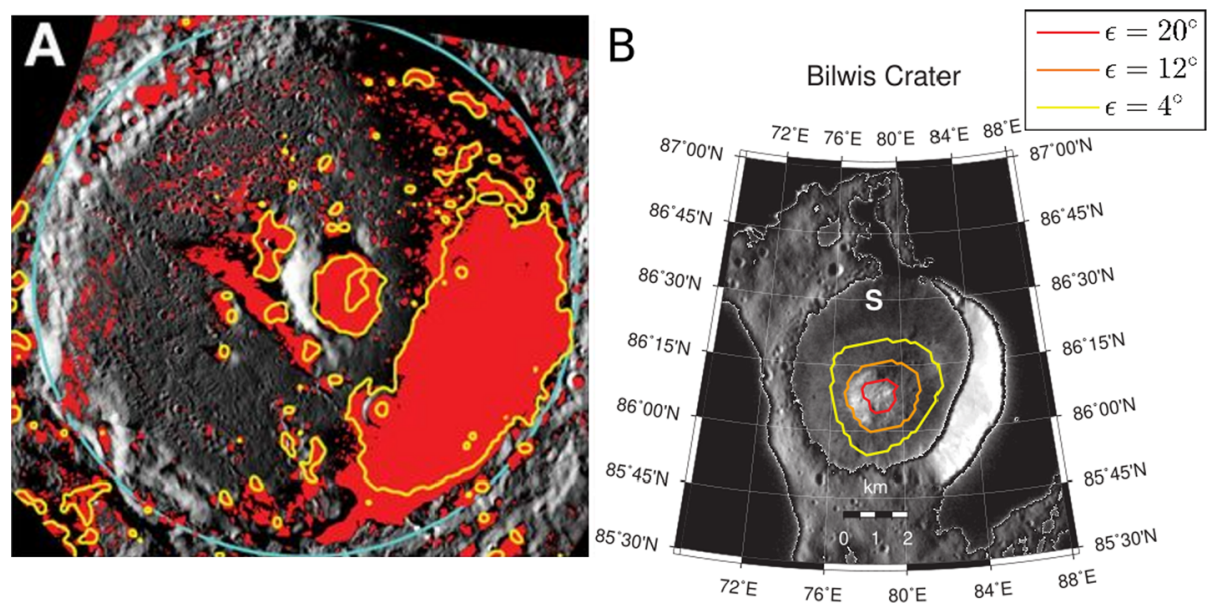

Fig. 8 Ice deposits within PSRs on Mercury and Ceres. A) High-reflectance surface within Prokofiev crater on Mercury; the radar-bright region (yellow contour) is located within a PSR (red). Image adapted from Chabot et al. (2014); copyright by GSA. B) Bilwis crater on Ceres with a bright crater floor deposit. Colored contours are boundaries of PSRs at various values of the axis tilt $\varepsilon$. No comparable relation between ice deposits and PSRs has yet been identified on the Moon. Image adapted from Ermakov et al. (2017), copyright by $\mathrm{AGU}$

1979; Lanzerotti et al. 1981). Surface ice is further eroded by meteoric impact vaporization and meteoric impact ejection (Farrell et al. 2019), although impact ejecta can also protect volatiles from further sublimation. The surfaces of airless bodies experience a statistical turnover due to meteor impacts (Gault et al. 1974; Arnold 1975; Morris 1978; Crider and Vondrak 2003; Costello et al. 2020).

\subsection{Mercury}

The axis tilt of Mercury is currently only 2 arc minutes and has remained near zero for at least the past $3.5 \mathrm{Gyr}$, so it has been anticipated that Mercury has permanently shadowed regions that may have trapped water ice (Thomas 1974). Modeling predicted the surface temperatures in these hypothetical shadowed regions would be low enough for water ice to be stable (Paige et al. 1992; Vasavada et al. 1999). Radar observations revealed highly reflective regions near Mercury's north and south pole with a high circular polarization ratio (Slade et al. 1992; Harmon and Slade 1992; Butler and Muhleman 1993; Harmon et al. 1994). Analysis of these radar data suggest water ice deposits which are very pure and at least several meters thick. Radar observations alone are not a definitive indicator of water ice; for instance, Starukhina $(2001,2012)$ suggested the dielectric properties of silicates are uncertain at low temperatures and may be an alternative explanation of the radar observations ("cold silicate hypothesis"). However, observations by the MESSENGER spacecraft support the presence of water ice.

The MESSENGER spacecraft found enhanced hydrogen concentrations in the polar region from neutron measurements (Neumann et al. 2013) and optical evidence for water ice on the surface in the PSRs (Chabot et al. 2014, 2018a). The areas of high radar backscatter are strongly correlated with areas that are in permanent shadow (Fig. 8A) and with the predicted abundance of thermally stable water ice (Paige et al. 2013; Chabot et al. 2018b). According to MESSENGER near-infrared reflectance measurements of the surface, the coldest 
areas are bright, whereas areas with higher predicted temperatures, where water ice is expected to be short-lived on the very surface but long-lived at shallow depth, are dark (Paige et al. 2013). The dark surface deposits may be devolatilized sublimation lag deposits (Neumann et al. 2013; Paige et al. 2013; Hamill et al. 2020) or due to radiation processing of various cold-trapped species (Crites et al. 2013; Delitsky et al. 2017). Mercury's polar deposits have sharp boundaries, which suggests that the deposits are geologically young or that their boundaries are refreshed by an ongoing process (Chabot et al. 2018a). Radar data suggest that the ice deposits must be at least a few meters thick (several radar wavelengths), and they are likely no more than tens of meters thick (Susorney et al. 2019).

\subsection{The Moon}

PSRs can be mapped by illumination modeling (ray-tracing) with digital elevation maps, and have been identified down to a latitude of $\sim 60^{\circ}$ (McGovern et al. 2013). PSRs poleward of $80^{\circ}$ cover $1.6 \times 10^{4} \mathrm{~km}^{2}$ in the south polar region and $1.3 \times 10^{4} \mathrm{~km}^{2}$ in the north polar region (Mazarico et al. 2011; McGovern et al. 2013). Vice versa, some areas are sunlit up to $89 \%$ of time (Noda et al. 2008) and known as "peaks of eternal light", although the direct solar illumination is not perfectly continuous.

Cold traps, which lie within PSRs, have been mapped based on surface temperatures measured by the Diviner instrument on LRO (Paige et al. 2010a,b; Hayne et al. 2015; Williams et al. 2019; Schorghofer and Williams 2020; Fig. 6). Near the poles, the Moon's $1.54^{\circ}$ obliquity induces significant seasonal changes in surface temperatures, where seasons are defined by the 347 day draconic year. Summer cold traps, which are truly permanently shadowed, cover $1.3 \times 10^{4} \mathrm{~km}^{2}$ poleward of $80^{\circ} \mathrm{S}$ and $0.53 \times 10^{4} \mathrm{~km}^{2}$ poleward of $80^{\circ} \mathrm{N}$ when defined by a peak temperature of $110 \mathrm{~K}$ (Williams et al. 2019). This amounts to $0.05 \%$ of the global surface area. In winter, these areas increase by factors of 2.8 and 4.3 , respectively (Fig. 6). The temperatures of near-pole crater Faustini is $\sim 30-40 \mathrm{~K}$ in winter and $\sim 45-70 \mathrm{~K}$ in summer. While these temperatures are well below the threshold for water ice stability, they have significant effects on more volatile molecules, such as $\mathrm{CO}_{2}$. The lowest temperatures measured by Diviner are about $20 \mathrm{~K}$, and may be limited by the regional heat flow from the lunar mantle. On the other extreme, non-polar permanently shadowed regions at mid-latitudes have significant scattered light and can be as warm as $\sim 216 \mathrm{~K}$ with average temperatures of $\sim 134 \mathrm{~K}$.

Radar observations did not reveal signs of pure near-surface ice deposits as they did on Mercury (Nozette et al. 1996; Stacy et al. 1997; Simpson and Tyler 1999; Campbell et al. 2003), but neutron spectroscopy found the hydrogen concentration is enhanced in the polar regions (Feldman et al. 1998, 2000, 2001; Mitrofanov et al. 2010). The LCROSS impact into Cabeus crater released a variety of volatiles (including $\mathrm{H}_{2} \mathrm{O}, \mathrm{H}_{2} \mathrm{~S}, \mathrm{NH}_{3}, \mathrm{SO}_{2}$, and $\mathrm{C}_{2} \mathrm{H}_{4}$ ) and therefore provided direct evidence for these species in lunar cold traps (Colaprete et al. 2010). The concentration of water ice at the impact site was an estimated $5.6 \pm 2.9 \%$ by mass. There is also evidence for water ice beyond Cabeus crater, based on neutron counts (Feldman et al. 1998, 2000, 2001; Mitrofanov et al. 2010), ultraviolet spectroscopy (Gladstone et al. 2012; Hayne et al. 2015), near infrared spectroscopy (Fisher et al. 2017; Li et al. 2018), and depth-to-diameter ratios of craters (Rubanenko et al. 2019). The locations identified by these individual studies are sometimes inconsistent and contain some identifications of water ice beyond known cold traps in apparently illuminated terrain; ambiguities remain in the interpretation of these datasets. 


\subsection{Ceres}

The axis tilt of Ceres is small, and Hayne and Aharonson (2015) predicted the presence of PSRs before Dawn's arrival. Dawn determined the axis tilt to be $4.03^{\circ}$, and the PSRs of the northern polar region were mapped in two ways. Stereo imaging, more specifically stereo photogrammetry, was used to construct topographic shape models, and these were used to calculate the extent of shadows. In this way, the northern PSRs were mapped and found to cover $1,800 \mathrm{~km}^{2}$ or $0.13 \%$ of the hemisphere (Schorghofer et al. 2016). Another approach was to stack images from various local times acquired close to the northern summer solstice. This method, of higher spatial resolution, identified hundreds of PSRs totalling 2,200 km of area. Due to illumination conditions, no comparable analyses could be carried out for the southern polar region, but statistically the topographies of the polar regions are similar.

Some scattered light is available even within shadowed regions, and searches were conducted for ice deposits within PSRs. Bright deposits were discovered in a small number of PSRs (Platz et al. 2016; Ermakov et al. 2017). The largest bright deposit is within Bilwis crater (Fig. 8B). In Zatik crater, bright material extends into sunlight, where it was spectroscopically identified as $\mathrm{H}_{2} \mathrm{O}$ ice (Platz et al. 2016). Observations by Dawn also led to an accurate measurement of the moments of inertia of Ceres, which made it possible to reliably backward integrate the obliquity history. The obliquity (axis tilt) of Ceres varies between $2^{\circ}$ and $20^{\circ}$ with a period of $24.5 \mathrm{kyr}$ (Bills and Scott 2017; Ermakov et al. 2017). These obliquity oscillations may also explain why only a small fraction of PSRs has bright deposits. At maximum axis tilt only a handful of PSRs remain (Ermakov et al. 2017).

\subsection{Micro Cold Traps}

While orbital measurements have succeeded in predicting and observing cold traps on scales of $100 \mathrm{~s}$ of meters to $10 \mathrm{~s}$ of kilometers, the prevalence of cold traps on smaller scales has to be inferred statistically. At finer resolution the area of PSRs increases, because the shadow of a large hill is still a contiguous shadow when viewed at finer resolution and shadows of smaller hills are added (Petrov et al. 2003; Gläser et al. 2014). Hayne et al. (2021) found that $10 \%$ of the PSR area on the Moon is in patches smaller than $100 \mathrm{~m}$ in diameter. The regolith on airless bodies is sufficiently insulating to at least $\mathrm{cm}$-scales, assuming typical roughness values, to maintain temperature gradients of more than $100 \mathrm{~K}$ (Bandfield et al. 2015). In theory, this should create heterogeneous terrains of illuminated surfaces and "micro" cold traps extending to vast regions beyond the larger "macro" cold traps (Rubanenko et al. 2018; Hayne et al. 2021). The effects of regolith physical properties on micro cold traps and the subsurface temperatures are areas for future study.

\section{Water Cycles}

In lieu of a summary, we consider the water cycle from source to sink, or rather semi-cycle, since the water molecules are not recycled.

\subsection{Sources}

Molecular water can originate from exogenic and endogenic sources. Exogenic sources are comets and hydrated meteoroids. In the long-term, the mass flux of the impactor population is dominated by the largest objects, so there is a probabilistic factor in the amount delivered. 
For example, Mercury's massive ice deposits could have resulted from a recent large comet impact (Moses et al. 1999; Ernst et al. 2020; Chabot et al. 2018a), which would explain the apparent difference in the abundance of cold trapped ice compared to the Moon.

In solar-wind generated water, the hydrogen is exogenic and the oxygen endogenic. The solar wind contains almost no deuterium (Stephant and Robert 2014), and an isotopic measurement $(\mathrm{D} / \mathrm{H})$ of ice deposits could therefore constrain its origin. Formation and retention of $\mathrm{OH}, \mathrm{H}_{2}$, and $\mathrm{H}_{2} \mathrm{O}$ are ongoing surficial processes (Sects. 2-4). Solar-wind implantation of hydrogen induces the formation of hydroxyls. Hydroxyls can then combine to form $\mathrm{H}_{2} \mathrm{O}$. This recombinative desorption requires high temperatures, such as those reached on the dayside of Mercury, or heating by impacts, which occurs on all large airless bodies. Many questions remain. On the Moon, only relatively large meteoroids release water group species, whereas dust-sized impactors do not, suggesting a desiccated layer is present (Sect. 5). The amplitudes of diurnal and latitude variations of the surficial hydroxyl concentration are insufficiently understood, as results of various spectroscopic analyses are inconsistent with one another and with some of the theoretical kinetics derived from laboratory measurements.

Endogenic outgassing of primordial water is more likely in the distant past than in recent history (Needham and Kring 2017; Deutsch et al. 2019; Head et al. 2020). At this point, the major source of molecular water has not been determined on either Mercury or the Moon. In the case of Ceres (Sect. 6), its own ice-rich crust is presumably the major source of its cold-trapped water. Even dry impactors can release water vapor on Ceres and even without impactors, indigenous water molecules slowly diffuse through the overlying ice-free surface layer. Further in the past, cryovolcanoes may have brought ice from greater depths to the surface of Ceres (Ruesch et al. 2016).

\subsection{Exospheric Transport and Sinks}

On large airless bodies, water molecules undergo ballistic hops rather than escaping to space (Sect. 7). Through a sequence of such hops, water may be transported from any location on the surface to cold traps. The nature of the interaction of returning water molecules upon contact with the pristine surface is uncertain. In one extreme the molecules thermally accommodate and leave the surface again, in the other they are chemically adsorbed. The massive ice deposits in the cold traps of Mercury must have arrived there somehow, but that ice could have resulted from a rare recent comet impact rather than been delivered steadily through exospheric transport. Observations of water group exospheres are rare. Nevertheless, a thermally accommodated water exosphere remains the standard theory awaiting confirmation or disproof.

Water molecules are lost due to gravitational escape, photo-destruction, cold-trapping, and possibly by dissociative chemisorption. On Mercury, photo-destruction is thought to be the major loss process, due to its proximity to the sun and high gravity. On Ceres, gravitational escape dominates. From that perspective, the Moon is expected to transport water more efficiently to the polar cold traps than these two other planetary bodies, yet the Moon appears to have a lower concentration of cold-trapped water ice than the other two bodies.

At low temperature, volatiles can accumulate over time even when exposed to vacuum. Permanently shadowed regions (PSRs) are closely related to cold traps, although they never perfectly coincide (Sect. 8). Thick ice deposits are found in the Hermean cold traps, often covered by a dark lag deposit. On the Moon, very little ice has been detected on the very surface of cold traps, but the LCROSS impact experiment and two sets of neutron spectroscopy measurements (one by the Lunar Prospector and the other by LRO) have provided clear evidence for a bulk-enrichment of hydrogen in the polar regions. On Ceres, the spin 
axis tilt varies periodically, so the present-day PSRs and cold traps are larger than the truly permanent PSRs and cold traps. Bright crater floor deposits are seen in several of the truly permanent PSRs. Cold-trapped water may subsequently be destroyed by space weathering (Farrell et al. 2019).

\subsection{Outlook}

The study of the Hermean, lunar, and Cerean water cycles has only just begun. Theories have been in place for decades, but they are far from established and some might not survive at all. Whereas interactions of solar wind protons with the surface have long been discussed, the quantitative aspects (such as mineral-dependent diffusivities of hydrogenated molecules and the corresponding activation energies, and the efficiency of $\mathrm{H}_{2}$ and $\mathrm{H}_{2} \mathrm{O}$ formation) are only slowly becoming clear. There were also observational surprises, such as the existence of a latitude-dependent hydroxyl population on the Moon and the fact that water group species are released during meteoroid showers, in excess of the water contained in the impacting meteoroids. Lateral transport in the gravitationally-bound surface-bounded water exospheres of the large airless bodies remains a theoretical concept, as there is insufficient observational data to put these models to a test. Observations that distinguish between surficial $\mathrm{OH}$ and $\mathrm{H}_{2} \mathrm{O}$ and exospheric water group neutrals and ions would provide important constraints to decipher the driving physics. Cold trapping of water ice is expected to occur on all three bodies, but the question is confounded by significant discrepancies among proxy measurements of the water content in the lunar polar regions.

This last topic will surely benefit from in-situ measurements by upcoming landed missions to the polar regions of the Moon. The Polar Resources Ice Mining Experiment1 (PRIME-1), MoonRanger and NASA's Volatiles Investigating Polar Exploration Rover (VIPER) will explore the south polar region of the Moon in 2022 and 2023. Understanding the distribution of water ice at the lunar poles is of major international interest; further planned missions to the south pole include the Lunar Polar Exploration Mission (LUPEX, a collaboration between the Japanese and Indian space agencies), Chang'e 6 and 7 (by the Chinese National Space Administration), Luna 25 (by Russia's Roscosmos), and Luna 27 (a collaboration between Roscosmos and the European Space Agency). Commercially operated lunar landers currently under development also plan to carry science payloads that will characterize the lunar exosphere and surface thermal environment at and beyond the poles. Several innovative orbital instruments will also search for volatiles. Observations of the lunar surface (over an extended infrared spectra range and new radar wavelengths) and exosphere by the Chandrayaan 2 orbiter are underway since 2019. A group of thirteen CubeSats, including Lunar Flashlight, Lunar IceCube, and LunaH-Map, is expected to be launched in 2021. ShadowCam on the Korea Pathfinder Lunar Orbiter, launching in 2022, is designed to image shadowed regions using scattered light. Lunar Trailblazer will carry a short-wave infrared imaging spectrometer that is an improvement over $\mathrm{M}^{3}$. With or without these new missions, laboratory experiments using simulants and returned samples along with comprehensive and capable theoretical models are important tools for developing an understanding of the processes that govern the presence of water on the surfaces and in the exospheres of the large airless bodies of the inner solar system.

Acknowledgements The authors are grateful for the hospitality of the International Space Science Institute (ISSI) during the Workshop on "Surface Bounded Exospheres and Interactions in the Solar System" that took place January 20-24, 2020 in Bern, Switzerland. OT gratefully acknowledges the scientific contributions of NASA Heliophysicist Richard Hartle who passed away on 19 February 2019 at the age of 82. AB was partially supported by Russian Science Foundation grant no. 20-12-00105. BTG appreciated SSERVI support 
through NNA14AB02A (VORTICES). BJ and TO acknowledge support through SSERVI REVEALS. NS was supported by SSERVI cooperative agreement NNH16ZDA001N (TREX). PP acknowledges support from SSERVI through the LEADER and ICE Five-O teams. OT was supported in part by SSERVI LEADER. CW was partially supported by RFBR-DFG grant no. WO 1800/7-1.

Open Access This article is licensed under a Creative Commons Attribution 4.0 International License, which permits use, sharing, adaptation, distribution and reproduction in any medium or format, as long as you give appropriate credit to the original author(s) and the source, provide a link to the Creative Commons licence, and indicate if changes were made. The images or other third party material in this article are included in the article's Creative Commons licence, unless indicated otherwise in a credit line to the material. If material is not included in the article's Creative Commons licence and your intended use is not permitted by statutory regulation or exceeds the permitted use, you will need to obtain permission directly from the copyright holder. To view a copy of this licence, visit http://creativecommons.org/licenses/by/4.0/.

\section{References}

M.F. A'Hearn, P.D. Feldman, Water vaporization on Ceres. Icarus 98, 54-60 (1992). https://doi.org/10.1016/ 0019-1035(92)90206-M

J.R. Arnold, Monte Carlo simulation of turnover processes in the lunar regolith. Proc. Lunar Planet. Sci. Conf. 6, 2375-2395 (1975)

J.R. Arnold, Ice in the lunar polar regions. J. Geophys. Res. 84(B10), 5659 (1979). https://doi.org/10.1029/ JB084iB10p05659

J.L. Bandfield, P.O. Hayne, J.-P. Williams, B.T. Greenhagen, D.A. Paige, Lunar surface roughness derived from LRO Diviner Radiometer observations. Icarus 248, 357-372 (2015). https://doi.org/10.1016/j. icarus.2014.11.009

J.L. Bandfield, M.J. Poston, R.L. Klima, C.S. Edwards, Widespread distribution of $\mathrm{OH} / \mathrm{H}_{2} \mathrm{O}$ on the lunar surface inferred from spectral data. Nat. Geosci. 11, 173-177 (2018). https://doi.org/10.1038/s41561018-0065-0

A.T. Basilevsky, A.M. Abdrakhimov, V.A. Dorofeeva, Water and other volatiles on the Moon: a review. Sol. Syst. Res. 46(2), 89-107 (2012). https://doi.org/10.1134/S0038094612010017

M. Benna, P.R. Mahaffy, J.S. Halekas, R.C. Elphic, G.T. Delory, Variability of helium, neon, and argon in the lunar exosphere as observed by the LADEE. Geophys. Res. Lett. 42, 3723-3729 (2015a). https://doi. org/10.1002/2015GL064120

M. Benna, D.M. Hurley, T.J. Stubbs, P.R. Mahaffy, R.C. Elphic, Observations of meteoroidal water in the lunar exosphere by the LADEE NMS instrument, in Annual Meeting of the Lunar Exploration Analysis Group, Columbia, MD (2015b)

M. Benna, D.M. Hurley, T.J. Stubbs, P.R. Mahaffy, R.C. Elphic, Lunar soil hydration constrained by exospheric water liberated by meteoroid impacts. Nat. Geosci. 12, 333-338 (2019). https://doi.org/10.1038/ s41561-019-0345-3

A.A. Berezhnoi, B.A. Klumov, Lunar ice: can its origin be determined? JETP Lett. 68, 163-167 (1998). https://doi.org/10.1134/1.567840

A.A. Berezhnoy, N. Hasebe, T. Hiramoto, B.A. Klumov, Possibility of the presence of $\mathrm{S}, \mathrm{SO}_{2}$, and $\mathrm{CO}_{2}$ at the poles of the Moon. Publ. Astron. Soc. Jpn. 55, 859-870 (2003). https://doi.org/10.1093/pasj/55.4. 859

B.G. Bills, B.R. Scott, Secular obliquity variations of Ceres and Pallas. Icarus 284, 59-69 (2017). https://doi. org/10.1016/j.icarus.2016.10.024

G. Blanford, P. Borgesen, M. Maurette, W. Moller, B. Monart, Hydrogen and water desorption on the Moon: approximate on-line simulations, in Lunar Bases and Space Activities of the 21st Century, ed. by W.W. Mendell (Lunar and Planetary Institute, Houston, 1985), pp. 603-610

J.W. Boyce, Y. Liu, G.R. Rossman, Y. Guan, J.M. Eiler, E.M. Stolper, L.A. Taylor, Lunar apatite with terrestrial volatile abundances. Nature 466(7305), 466-469 (2010). https://doi.org/10.1038/nature09274

J.P. Bradley, H.A. Ishii, J.J. Gillis-Davis et al., Detection of solar wind-produced water in irradiated rims on silicate minerals. Proc. Natl. Acad. Sci. 111(5), 1732-1735 (2014). https://doi.org/10.1073/pnas. 1320115111

R.T. Brinkmann, Departures from Jeans' escape rate for H and He in the Earth's atmosphere. Planet. Space Sci. 18, 449-478 (1970). https://doi.org/10.1016/0032-0633(70)90124-8

D. Buhl, W.J. Welch, D.G. Rea, Reradiation and thermal emission from illuminated craters on the lunar surface. J. Geophys. Res. 73(16), 5281-5295 (1968). https://doi.org/10.1029/JB073i016p05281 
D. Burke, C. Dukes, J.-H. Kim, J. Shi, M. Famá, R. Baragiola, Solar wind contribution to surficial lunar water: laboratory investigations. Icarus 211, 1082 (2011). https://doi.org/10.1016/j.icarus.2010.11.007

B.J. Butler, D.O. Muhleman, Mercury: full-disk radar images and the detection and stability of ice at the north pole. J. Geophys. Res. 98(E8), 15003-15023 (1993). https://doi.org/10.1029/93JE01581

B.J. Butler, The migration of volatiles on the surfaces of Mercury and the Moon. J. Geophys. Res., Planets 102, 19283-19291 (1997). https://doi.org/10.1029/97JE01347

B.A. Campbell, D.B. Campbell, J.F. Chandler, A.A. Hine, M.C. Nolan, P.J. Perillat, Radar imaging of the lunar poles. Nature 426(6963), 137-138 (2003). https://doi.org/10.1038/426137a

N.L. Chabot, C.M. Ernst, B.W. Denevi et al., Images of surface volatiles in Mercury's polar craters acquired by the MESSENGER spacecraft. Geology 42(12), 1051-1054 (2014). https://doi.org/10.1130/ G35916.1

N.L. Chabot, D.J. Lawrence, G.A. Neumann et al., Mercury's polar deposits, in Mercury: The View After MESSENGER (Cambridge University Press, Cambridge, 2018a). https://doi.org/10.1017/ 9781316650684.014

N.L. Chabot, E.E. Shread, J.K. Harmon, Investigating Mercury's South polar deposits: Arecibo radar observations and high-resolution determination of illumination conditions. J. Geophys. Res., Planets 123(2), 666-681 (2018b). https://doi.org/10.1002/2017JE005500

M.J. Cintala, Impact-induced thermal effects in the lunar and mercurian regoliths. J. Geophys. Res., Planets 97(E1), 947-973 (1992). https://doi.org/10.1029/91JE02207

R.N. Clark, Detection of adsorbed water and hydroxyl on the Moon. Science 326(5952), 562-564 (2009). https://doi.org/10.1126/science. 1178105

A. Colaprete, P. Schultz, J. Heldmann et al., Detection of water in the LCROSS ejecta plume. Science 330(6003), 463-468 (2010). https://doi.org/10.1126/science.1186986

J.-P. Combe, T.B. McCord, F. Tosi et al., Detection of local $\mathrm{H}_{2} \mathrm{O}$ exposed at the surface of Ceres. Science 353, aaf3010 (2016). https://doi.org/10.1126/science.aaf3010

J.-P. Combe, A. Raponi, F. Tosi et al., Exposed $\mathrm{H}_{2} \mathrm{O}$-rich areas detected on Ceres with the dawn visible and InfraRed mapping spectrometer. Icarus 318, 22-41 (2019). https://doi.org/10.1016/j.icarus.2017.12.008

E.S. Costello, R.R. Ghent, P.G. Lucey, The mixing of lunar regolith: vital updates to a canonical model. Icarus 314, 327-344 (2020). https://doi.org/10.1016/j.icarus.2018.05.023

P.B. Crandall, J.J. Gillis-Davis, R.I. Kaiser, Untangling the origin of molecular hydrogen in the lunar exosphere. Astrophys. J. 887, 27 (2019). https://doi.org/10.3847/1538-4357/ab4e1f

D.H. Crider, R.R. Vondrak, The solar wind as a possible source of lunar polar hydrogen deposits. J. Geophys. Res., Planets 105, 26773-26782 (2000). https://doi.org/10.1029/2000JE001277

D.H. Crider, R.R. Vondrak, Space weathering effects on lunar cold trap deposits. J. Geophys. Res., Planets 108(E7), 5079 (2003). https://doi.org/10.1029/2002JE002030

S.T. Crites, P.G. Lucey, D.J. Lawrence, Proton flux and radiation dose from galactic cosmic rays in the lunar regolith and implications for organic synthesis at the poles of the Moon and Mercury. Icarus 226(2), 1192-1200 (2013). https://doi.org/10.1016/j.icarus.2013.08.003

J. Crovisier, The photodissociation of water in cometary atmospheres. Astron. Astrophys. 213, 459-464 (1989)

R.T. Daly, P.H. Schultz, The delivery of water by impacts from planetary accretion to present. Sci. Adv. 4, eaar2632 (2018). https://doi.org/10.1126/sciadv.aar2632

M.L. Delitsky, D.A. Paige, M.A. Siegler et al., Ices on Mercury: chemistry of volatiles in permanently cold areas of Mercury's north polar region. Icarus 281, 19-31 (2017). https://doi.org/10.1016/j.icarus.2016. 08.006

A.N. Deutsch, J.W. Head III., G.A. Neumann, Age constraints of Mercury’s polar deposits suggest recent delivery of ice. Earth Planet. Sci. Lett. 520, 26-33 (2019). https://doi.org/10.1016/j.eps1.2019.05.027

Y. Du, N.G. Petrik, N.A. Deskins et al., Hydrogen reactivity on highly-hydroxylated $\mathrm{TiO}_{2}(110)$ surfaces prepared via carboxylic acid adsorption and photolysis. Phys. Chem. Chem. Phys. 14, 3066 (2012). https://doi.org/10.1039/C1CP22515D

M.D. Dyar, C.A. Hibbitts, T.M. Orlando, Mechanisms for incorporation of hydrogen in and on terrestrial planetary surfaces. Icarus 208(1), 425-437 (2010). https://doi.org/10.1016/j.icarus.2010.02.014

A.I. Ermakov, E. Mazarico, S.E. Schroder et al., Ceres's obliquity history and implications for the permanently shadowed regions. Geophys. Res. Lett. 44, 2652-2661 (2017). https://doi.org/10.1002/ 2016GL072250

C.M. Ernst, N.L. Chabot, O.S. Barnouin, Examining the potential contribution of the Hokusai impact to water ice on Mercury. J. Geophys. Res., Planets 123, 2628-2646 (2020). https://doi.org/10.1029/ 2018JE005552

F.P. Fanale, J.R. Salvail, The water regime of asteroid (1) Ceres. Icarus 82(1), 97-110 (1989). https://doi.org/ 10.1016/0019-1035(89)90026-2 
W.M. Farrell, D.M. Hurley, M.I. Zimmerman, Solar wind implantation into lunar regolith: hydrogen retention in a surface with defects. Icarus 255, 116-126 (2015). https://doi.org/10.1016/j.icarus.2014.09.014

W.M. Farrell, D.M. Hurley, V.J. Esposito, J.L. McLain, M.I. Zimmerman, The statistical mechanics of solar wind hydroxylation at the Moon, within lunar magnetic anomalies, and at Phobos. J. Geophys. Res., Planets 122(1), 269-289 (2017). https://doi.org/10.1002/2016JE005168

W.M. Farrell, D.M. Hurley, M.J. Poston et al., The young age of the LAMP-observed frost in lunar polar cold traps. Geophys. Res. Lett. 46, 8680-8688 (2019). https://doi.org/10.1029/2019GL083158

W.C. Feldman, S. Maurice, A.B. Binder, B.L. Barraclough, R.C. Elphic, D.J. Lawrence, Fluxes of fast and epithermal neutrons from lunar prospector: evidence for water ice at the lunar poles. Science 281(5382), 1496-1500 (1998). https://doi.org/10.1126/science.281.5382.1496

W.C. Feldman, D.J. Lawrence, R.C. Elphic, B.L. Barraclough, S. Maurice, I. Genetay, A.B. Binder, Polar hydrogen deposits on the Moon. J. Geophys. Res., Planets 105(E2), 4175-4195 (2000). https://doi.org/ 10.1029/1999JE001129

W.C. Feldman, S. Maurice, D.J. Lawrence et al., Evidence for water ice near the lunar poles. J. Geophys. Res., Planets 106(E10), 23231-23251 (2001). https://doi.org/10.1029/2000JE001444

D. Fink, J. Krauser, D. Nagengast et al., Hydrogen implantation and diffusion in silicon and silicon dioxide. Appl. Phys. A 61(4), 381-388 (1995). https://doi.org/10.1007/BF01540112

E.A. Fisher, P.G. Lucey, M. Lemelin et al., Evidence for surface water ice in the lunar polar regions using reflectance measurements from the Lunar Orbiter Laser Altimeter and temperature measurements from the Diviner Lunar Radiometer Experiment. Icarus 292, 74-85 (2017). https://doi.org/10.1016/j.icarus. 2017.03.023

M. Formisano, M.C. De Sanctis, G. Magni, C. Federico, M.T. Capria, Ceres water regime: surface temperature, water sublimation and transient exo(atmo)sphere. Mon. Not. R. Astron. Soc. 455, 1892-1904 (2016). https://doi.org/10.1093/mnras/stv2344

J.W. Freeman Jr., H.K. Hills, The Apollo lunar surface water vapor event revisited. Geophys. Res. Lett. 18(11), 2109-2112 (1991). https://doi.org/10.1029/91GL02625

J.W. Freeman, H.K. Hills, R.A. Lindeman, R.R. Vondrak, Observations of water vapor ions at the lunar surface. Moon 8(1-2), 115-128 (1973). https://doi.org/10.1007/BF00562753

D.E. Gault, F. Hörz, D.E. Brownlee, J.B. Hartung, Mixing of the lunar regolith. Proc. Lunar Planet. Sci. Conf. 5, 2365-2386 (1974)

E.K. Gibson, Production of simple molecules on the surface of Mercury. Phys. Earth Planet. Inter. 15, 303 (1977). https://doi.org/10.1016/0031-9201(77)90038-3

G.R. Gladstone, K.D. Retherford, A.F. Egan et al., Far-ultraviolet reflectance properties of the Moon's permanently shadowed regions. J. Geophys. Res., Planets 117(E12), E00H04 (2012). https://doi.org/10.1029/ 2011JE003913

P. Gläser, F. Scholten, D. De Rosa et al., Illumination conditions at the lunar south pole using high resolution Digital Terrain Models from LOLA. Icarus 243, 78-90 (2014). https://doi.org/10.1016/j.icarus.2014.08. 013

T.D. Glotch, J.L. Bandfield, P.G. Lucey et al., Formation of lunar swirls by magnetic field standoff of the solar wind. Nat. Commun. 6, 6189 (2015). https://doi.org/10.1038/ncomms7189

D.B. Goldstein, J.V. Austin, E.S. Barker, R.S. Nerem, Short-time exosphere evolution following an impulsive vapor release on the Moon. J. Geophys. Res., Planets 106, 32841-32845 (2001). https://doi.org/10.1029/ 2000JE001326

R.O. Green, C. Pieters, P. Mouroulis et al., The Moon Mineralogy Mapper (M3) imaging spectrometer for lunar science: Instrument description, calibration, on-orbit measurements, science data calibration and on-orbit validation. J. Geophys. Res., Planets 116(E10), E00G19 (2011). https://doi.org/10.1029/ 2011JE003797

J.P. Greenwood, S. Itoh, N. Sakamoto, P. Warren, L. Taylor, H. Yurimoto, Hydrogen isotope ratios in lunar rocks indicate delivery of cometary water to the Moon. Nat. Geosci. 4, 79 (2011). https://doi.org/10. 1038/ngeo 1050

D.L. Griscom, Thermal bleaching of X-ray induced defect centers in high purity fused silica by diffusion of radiolytic molecular hydrogen. J. Non-Cryst. Solids 19(68), 301-325 (1984)

A. Grumpe, C. Wöhler, A.A. Berezhnoy, V.V. Shevchenko, Time-of-day-dependent behavior of surficial lunar hydroxyl/water: observations and modeling. Icarus 321, 486-507 (2019). https://doi.org/10.1016/j. icarus.2018.11.025

V. Gun'ko, V.I. Zarko, B.A. Chuikov et al., Temperature-programmed desorption of water from fumed silica, silica/titania, and silica/alumina. Int. J. Mass Spectrom. Ion Process. 172, 161 (1998). https://doi.org/10. 1016/S0168-1176(97)00269-3

C.D. Hamill, N.L. Chabot, E. Mazarico et al., New illumination and temperature constraints of Mercury's volatile polar deposits. Planet. Sci. J. 1, 57 (2020). https://doi.org/10.3847/PSJ/abb1c2 
B. Hapke, Bidirectional reflectance spectroscopy. 6. Effects of porosity. Icarus 195(2), 918-926 (2008). https://doi.org/10.1016/j.icarus.2008.01.003

J.K. Harmon, M.A. Slade, Radar mapping of Mercury: full-disk images and polar anomalies. Science 258(5082), 640-643 (1992). https://doi.org/10.1126/science.258.5082.640

J.K. Harmon, M.A. Slade, R.A. Velez, A. Crespo, M.J. Dryer, J.M. Johnson, Radar mapping of Mercury's polar anomalies. Nature 369(6477), 213-215 (1994). https://doi.org/10.1038/369213a0

R.E. Hartle, G.E. Thomas, Neutral and ion exosphere models for lunar hydrogen and helium. J. Geophys. Res. 79(10), 1519-1526 (1974). https://doi.org/10.1029/JA079i010p01519

P.O. Hayne, O. Aharonson, Thermal stability of ice on Ceres with rough topography. J. Geophys. Res. 120, 1567-1584 (2015). https://doi.org/10.1002/2015JE004887

P.O. Hayne, A.P. Ingersoll, D.A. Paige et al., New approaches to lunar ice detection and mapping, Keck Institute for Space Studies Report (2014). https://resolver.caltech.edu/CaltechAUTHORS:20190213134457058

P.O. Hayne, A. Hendrix, E. Sefton-Nash, Evidence for exposed water ice in the Moon's south polar regions from Lunar Reconnaissance Orbiter ultraviolet albedo and temperature measurements. Icarus $\mathbf{2 5 5}$, 58-69 (2015). https://doi.org/10.1016/j.icarus.2015.03.032

P.O. Hayne, O. Aharonson, N. Schorghofer, Micro cold traps on the Moon. Nat. Astron. 5, 169-175 (2021). https://doi.org/10.1038/s41550-020-1198-9

J.W. Head, L. Wilson, A.N. Deutsch, M.J. Rutherford, A.E. Saal, Volcanically-induced transient atmospheres on the Moon: assessment of duration, significance and contributions to polar volatile traps. Geophys. Res. Lett. 47, e2020GL089509 (2020). https://doi.org/10.1029/2020GL089509

M.A. Henderson, The interaction of water with solid surfaces: fundamental aspects revisited. Surf. Sci. 46, 1-308 (1994). https://doi.org/10.1016/S0167-5729(01)00020-6

A.R. Hendrix, K.D. Retherford, G.R. Gladstone et al., The lunar far-UV albedo: indicator of hydration and weathering. J. Geophys. Res., Planets 117, E12001 (2012). https://doi.org/10.1029/2012JE004252

A.R. Hendrix, D. Hurley, K.D. Retherford et al., Diurnally migrating lunar water: evidence from ultraviolet data. Geophys. Res. Lett. 46, 2417-2424 (2019). https://doi.org/10.1029/2018GL081821

M. Hess, C. Wöhler, M. Bhatt et al., Processes governing the VIS/NIR spectral reflectance behavior of lunar swirls. Astron. Astrophys. 639, A12 (2020). https://doi.org/10.1051/0004-6361/201937299

R.R. Hodges Jr., Helium and hydrogen in the lunar atmosphere. J. Geophys. Res. 78(34), 8055-8064 (1973). https://doi.org/10.1029/JA078i034p08055

R.R. Hodges Jr., Exospheric transport restrictions on water ice in lunar polar traps. Geophys. Res. Lett. 18(11), 2113-2116 (1991). https://doi.org/10.1029/91GL02533

R.R. Hodges Jr., Ice in the lunar polar regions revisited. J. Geophys. Res., Planets 107(E2), 5011 (2002). https://doi.org/10.1029/2000JE001491

R.R. Hodges Jr., Methane in the lunar exosphere: implications for solar wind carbon escape. Geophys. Res. Lett. 43, 6742-6748 (2016). https://doi.org/10.1002/2016GL068994

C.I. Honniball, P.G. Lucey, C.M. Ferrari-Wong et al., Telescopic observations of lunar hydration: variations and abundance. J. Geophys. Res., Planets 125, e2020JE006484 (2020). https://doi.org/10.1029/ 2020JE006484

C.I. Honniball, P.G. Lucey, S. Li et al., Molecular water detected on the sunlit Moon by SOFIA. Nat. Astron. 5, 121-127 (2021). https://doi.org/10.1038/s41550-020-01222-X

L.L. Hood, G. Schubert, Lunar magnetic anomalies and surface optical properties. Science 208(4439), 49-51 (1980). https://doi.org/10.1126/science.208.4439.49

R.M. Housley, R.W. Grant, N.E. Paton, Origin and characteristics of excess Fe metal in lunar glass welded aggregates. Geochim. Cosmochim. Acta, Suppl. 4 3, 2737-2749 (1973)

W.F. Huebner, J. Mukherjee, Photoionization and photodissociation rates in solar and blackbody radiation fields. Planet. Space Sci. 106, 11-45 (2015). https://doi.org/10.1016/j.pss.2014.11.022

H. Hui, A.H. Peslier, Y. Zhang, C.R. Neal, Water in lunar anorthosites and evidence for a wet early Moon. Nat. Geosci. 6, 177 (2013). https://doi.org/10.1038/ngeo1735

D.M. Hurley, J.C. Cook, K.D. Retherford et al., Contributions of solar wind and micrometeoroids to molecular hydrogen in the lunar exosphere. Icarus 283, 31-37 (2017). https://doi.org/10.1016/j.icarus.2016.04.019

A.S. Ichimura, A.P. Zent, R.C. Quinn, M.R. Sanchez, L.A. Taylor, Hydroxyl (OH) production on airless planetary bodies: evidence from $\mathrm{H}^{+} / \mathrm{D}^{+}$ion-beam experiments. Earth Planet. Sci. Lett. 345-348, 90-94 (2012). https://doi.org/10.1016/j.epsl.2012.06.027

A.P. Ingersoll, T. Svitek, B.C. Murray, Stability of polar frosts in spherical bowl-shaped craters on the Moon, Mercury, and Mars. Icarus 100(1), 40-47 (1992). https://doi.org/10.1016/0019-1035(92)90016-Z

Y. Ishibe, H. Oyama, Reduction of metal oxide layer with hydrogen atoms dissociated on a hot rhenium filament. J. Nucl. Mater. 85, 1191 (1979). https://doi.org/10.1016/0022-3115(79)90423-9

Y.D. Jia, M.N. Villarreal, C.T. Russell, Possible Ceres bow shock surfaces based on fluid models. J. Geophys. Res. Space Phys. 122, 4976-4987 (2017). https://doi.org/10.1002/2016JA023712 
F.S. Johnson, Lunar atmosphere. Rev. Geophys. 9(3), 813-823 (1971). https://doi.org/10.1029/ RG009i003p00813

B.M. Jones, A. Aleksandrov, K. Hibbitts, M.D. Dyar, T.M. Orlando, Solar wind-induced water cycle on the Moon. Geophys. Res. Lett. 45(20), 10,959-10,967 (2018). https://doi.org/10.1029/2018GL080008

B.M. Jones, M. Sarantos, T.M. Orlando, A new in situ quasi-continuous solar-wind source of molecular water on Mercury. Astrophys. J. 891(2), L43 (2020). https://doi.org/10.3847/2041-8213/ab6bda

R. Killen, W.-H. Ip, The surface-bounded atmospheres of Mercury and the Moon. Rev. Geophys. 37, 361-406 (1999). https://doi.org/10.1029/1999RG900001

R. Killen, M.H. Burger, R.J. Vervack Jr., T.A. Cassidy, Understanding Mercury's exosphere: models derived from MESSENGER observations, in Mercury: The View After MESSENGER (Cambridge University Press, Cambridge, 2018). https://doi.org/10.1017/9781316650684.016

R. Klima, J. Cahill, J. Hagerty, D. Lawrence, Remote detection of magmatic water in Bullialdus crater on the Moon. Nat. Geosci. 6(9), 737-741 (2013). https://doi.org/10.1038/ngeo1909

J.L. Kloos, J.E. Moores, J. Sangha et al., The temporal and geographic extent of seasonal cold trapping on the Moon. J. Geophys. Res., Planets 124, 1935-1944 (2019). https://doi.org/10.1029/2019JE006003

G. Kramer et al., M3 spectral analysis of lunar swirls and the link between optical maturation and surface hydroxyl formation at magnetic anomalies. J. Geophys. Res. 116, E00G18 (2011)

M. Küppers, L. O'Rourke, D. Bockelée-Morvan et al., Localized sources of water vapour on the dwarf planet (1) Ceres. Nature 505, 525-527 (2014). https://doi.org/10.1038/nature12918

M.E. Landis, S. Byrne, N. Schorghofer et al., Conditions for sublimating water ice to supply Ceres' exosphere. J. Geophys. Res. 122, 1984-1995 (2017). https://doi.org/10.1002/2017JE005335

M.E. Landis, S. Byrne, J.-Ph. Combe et al., Water vapor contribution to Ceres' exosphere from observed surface ice and postulated ice-exposing impacts. J. Geophys. Res., Planets 124, 61-75 (2019). https:// doi.org/10.1029/2018JE005780

L.J. Lanzerotti, W.L. Brown, R.E. Johnson, Ice in the polar regions of the Moon. J. Geophys. Res. 86, 3949 (1981). https://doi.org/10.1029/JB086iB05p03949

D.J. Lawrence, A tale of two poles: toward understanding the presence, distribution, and origin of volatiles at the polar regions of the Moon and Mercury. J. Geophys. Res., Planets 122(1), 21-52 (2017). https://doi. org/10.1002/2016JE005167

S. Li, I. Garrick-Bethell, Surface water at lunar magnetic anomalies. Geophys. Res. Lett. 46(24), 14318-14327 (2019). https://doi.org/10.1029/2019GL084890

S. Li, R.E. Milliken, Water on the surface of the Moon as seen by the Moon Mineralogy Mapper: distribution, abundance, and origins. Sci. Adv. 3, e1701471 (2017). https://doi.org/10.1126/sciadv.1701471

S. Li, P.G. Lucey, R.E. Milliken et al., Direct evidence of surface exposed water ice in the lunar polar regions. Proc. Natl. Acad. Sci. 115(36), 8907-8912 (2018). https://doi.org/10.1073/pnas.1802345115

J.Y. Li, S.E. Schröder, S. Mottola et al., Spectrophotometric modeling and mapping of Ceres. Icarus 322 , 144-167 (2019). https://doi.org/10.1016/j.icarus.2018.12.038

Y. Liu, Y. Guan, Y. Zhang, G.R. Rossman, J.M. Eiler, L.A. Taylor, Direct measurement of hydroxyl in the lunar regolith and the origin of lunar surface water. Nat. Geosci. 5(11), 779-782 (2012). https://doi.org/ $10.1038 /$ ngeo1601

G.G. Managadze, V.T. Cherepin, Y.G. Shkuratov, V.N. Kolesnik, A.E. Chumikov, Simulating $\mathrm{OH} / \mathrm{H}_{2} \mathrm{O}$ formation by solar wind at the lunar surface. Icarus 215, 449 (2011). https://doi.org/10.1016/j.icarus.2011. 06.025

P.L. Mattern, G.J. Thomas, W. Bauer, Hydrogen and helium implantation in vitreous silica. J. Vac. Sci. Technol. 13, 430-436 (1976). https://doi.org/10.1116/1.568938

E. Mazarico, G.A. Neumann, D.E. Smith, M.T. Zuber, M.H. Torrence, Illumination conditions of the lunar polar regions using LOLA topography. Icarus 211(2), 1066-1081 (2011). https://doi.org/10.1016/j. icarus.2010.10.030

W.E. McClintock, T.A. Cassidy, A.W. Merkel et al., Observations of Mercury's exosphere: composition and structure, in Mercury: The View After MESSENGER (Cambridge University Press, Cambridge, 2018). https://doi.org/10.1017/9781316650684.015

T.B. McCord, L.A. Taylor, J.P. Combe, G. Kramer, C.M. Pieters, J.M. Sunshine, R.N. Clark, Sources and physical processes responsible for $\mathrm{OH} / \mathrm{H}_{2} \mathrm{O}$ in the lunar soil as revealed by the Moon Mineralogy Mapper (M3). J. Geophys. Res., Planets 116(4), 1-22 (2011). https://doi.org/10.1029/2010JE003711

J.A. McGovern, D.B. Bussey, B.T. Greenhagen, D.A. Paige, J.T. Cahill, P.D. Spudis, Mapping and characterization of non-polar permanent shadows on the lunar surface. Icarus 223(1), 566-581 (2013). https:// doi.org/10.1016/j.icarus.2012.10.018

D.S. McKay, G. Heiken, A. Basu et al., The lunar regolith, in Lunar Sourcebook, ed. by G.H. Heiken et al. (Cambridge University Press, New York, 1991), pp. 285-356, Chap. 7

A.J. McKay, D. Bodewitz, J.-Y. Li, Observational constraints on water sublimation from 24 Themis and 1 Ceres. Icarus 286, 308-313 (2017). https://doi.org/10.1016/j.icarus.2016.09.032 
H.Y. McSween Jr., J.P. Emery, A.S. Rivkin et al., Carbonaceous chondrites as analogs for the composition and alteration of Ceres. Meteorit. Planet. Sci. 53(9), 1793-1804 (2017). https://doi.org/10.1111/maps. 12947

R.E. Milliken, S. Li, Remote detection of widespread indigenous water in lunar pyroclastic deposits. Nat. Geosci. 10(8), 561-565 (2017). https://doi.org/10.1038/ngeo2993

I.G. Mitrofanov, A.B. Sanin, W.V. Boynton et al., Hydrogen mapping of the lunar south pole using the LRO neutron detector experiment LEND. Science 330(6003), 483-486 (2010). https://doi.org/10.1126/ science. 1185696

J.E. Moores, Lunar water migration in the interval between large impacts: heterogeneous delivery to permanently shadowed regions, fractionation, and diffusive barriers. J. Geophys. Res., Planets 121, 46-60 (2016). https://doi.org/10.1002/2015JE004929

T.H. Morgan, D.E. Shemansky, Limits to the lunar atmosphere. J. Geophys. Res. 96(A2), 1351-1367 (1991). https://doi.org/10.1029/90JA02127

R.V. Morris, In situ reworking/gardening/of the lunar surface-Evidence from the Apollo cores, in Lunar and Planetary Science Conference Proceedings, vol. 9 (1978), pp. 1801-1811

J.I. Moses, K. Rawlins, L. Zahnle, L. Dones, External sources of water for Mercury's putative ice deposits. Icarus 137(2), 197-221 (1999). https://doi.org/10.1006/icar.1998.6036

A. Nathues, M. Hoffmann, M. Schaefer et al., Sublimation in bright spots on (1) Ceres. Nature 528, 237-240 (2015). https://doi.org/10.1038/nature15754

D.H. Needham, D.A. Kring, Lunar volcanism produced a transient atmosphere around the ancient Moon. Earth Planet. Sci. Lett. 478, 175-178 (2017). https://doi.org/10.1016/j.eps1.2017.09.002

C.E. Nelson, J.W. Elam, M.A. Cameron, M.A. Tolbert, S.M. George, Desorption of $\mathrm{H}_{2} \mathrm{O}$ from a hydroxylated single-crystal $\alpha-\mathrm{Al}_{2} \mathrm{O}_{3}$ (0001) surface. Surf. Sci. 416, 341 (1998). https://doi.org/10.1016/S00396028(98)00439-7

G.A. Neumann, J.F. Cavanaugh, X. Sun et al., Bright and dark polar deposits on Mercury: evidence for surface volatiles. Science 339(6117), 296-300 (2013). https://doi.org/10.1126/science.1229764

S.K. Noble, L.P. Keller, C.M. Pieters, Evidence of space weathering in regolith breccias I: lunar regolith breccias. Meteorit. Planet. Sci. 40(3), 397-408 (2005). https://doi.org/10.1111/j.1945-5100.2005.tb00390.x

H. Noda, H. Araki, S. Goossens et al., Illumination conditions at the lunar polar regions by KAGUYA (SELENE) laser altimeter. Geophys. Res. Lett. 35, L24203 (2008). https://doi.org/10.1029/2008GL035692

S. Nozette, C.L. Lichtenberg, P. Spudis et al., The Clementine bistatic radar experiment. Science 274(5292), 1495-1498 (1996). https://doi.org/10.1126/science.274.5292.1495

D.A. Paige, S.E. Wood, A.R. Vasavada, The thermal stability of water ice at the poles of Mercury. Science 258(5082), 643-646 (1992). https://doi.org/10.1126/science.258.5082.643

D.A. Paige, M.C. Foote, B.T. Greenhagen et al., The lunar reconnaissance orbiter diviner lunar radiometer experiment. Space Sci. Rev. 150(1-4), 125-160 (2010a). https://doi.org/10.1007/s11214-009-9529-2

D.A. Paige, M.A. Siegler, J.A. Zhang et al., Diviner lunar radiometer observations of cold traps in the Moon's south polar region. Science 330(6003), 479-482 (2010b)

D.A. Paige, M.A. Siegler, J.K. Harmon et al., Thermal stability of volatiles in the north polar region of Mercury. Science 339(6117), 300-303 (2013). https://doi.org/10.1126/science.1231106

J. Papike, L. Taylor, S. Simon, Lunar minerals, in Lunar Sourcebook, vol. 5 (Cambridge University Press, Cambridge, 1991), pp. 121-182, Chap. 5

D.V. Petrov, Y.G. Shkuratov, D.G. Stankevich, V.V. Shevchenko, E.A. Kozlova, The area of cold traps on the lunar surface. Sol. Syst. Res. 37(4), 260-265 (2003). https://doi.org/10.1023/A:1025022130047

C.M. Pieters, J.N. Goswami, R.N. Clark et al., Character and spatial distribution of $\mathrm{OH} / \mathrm{H}_{2} \mathrm{O}$ on the surface of the Moon seen by M3 on Chandrayaan-1. Science 326, 468-572 (2009). https://doi.org/10.1126/science. 1178658

P.C. Pinet, V.V. Shevchenko, S.D. Chevrel, Y. Daydou, C. Rosemberg, Local and regional lunar regolith characteristics at Reiner Gamma formation: optical and spectroscopic properties from Clementine and Earth-based data. J. Geophys. Res. 105(E4), 9457-9475 (2000). https://doi.org/10.1029/1999JE001086

T. Platz, A. Nathues, N. Schorghofer et al., Surface water-ice deposits in the northern shadowed regions of Ceres. Nat. Astron. 1, 0007 (2016). https://doi.org/10.1038/s41550-016-0007

M.J. Poston, G.A. Grieves, A.B. Aleksandrov et al., Temperature programmed desorption studies of water interactions with Apollo lunar samples 12001 and 72501. Icarus 255, 24-29 (2015). https://doi.org/10. 1016/j.icarus.2014.09.049

A.E. Potter, Chemical sputtering could produce sodium vapor and ice on Mercury. Geophys. Res. Lett. 22, 3289 (1995). https://doi.org/10.1029/95GL03181

P. Prem, N.A. Artemieva, D.B. Goldstein, P.L. Varghese, L.M. Trafton, Transport of water in a transient impact-generated lunar atmosphere. Icarus 255, 148-158 (2015). https://doi.org/10.1016/j.icarus.2014. 10.017 
P. Prem, D.B. Goldstein, P.L. Varghese, L.M. Trafton, The influence of surface roughness on volatile transport on the Moon. Icarus 299, 31-45 (2018). https://doi.org/10.1016/j.icarus.2017.07.010

P. Prem, D.M. Hurley, D.B. Goldstein, P.L. Varghese, The evolution of a spacecraft-generated lunar exosphere. J. Geophys. Res., Planets 125, 8 (2020). https://doi.org/10.1029/2020JE006464

T.H. Prettyman, W.C. Feldman, H.Y. McSween et al., Dawn's gamma ray and neutron detector. Space Sci. Rev. 163, 371-459 (2011). https://doi.org/10.1007/s11214-011-9862-0

T.H. Prettyman, Y. Yamashita, M.J. Toplis et al., Extensive water ice within Ceres' aqueously altered regolith: evidence from nuclear spectroscopy. Science 355, 55-59 (2017). https://doi.org/10.1126/science. aah6765

A.S. Rivkin, J.Y. Li, R.E. Milliken et al., The surface composition of Ceres. Space Sci. Rev. 163, 95-116 (2011). https://doi.org/10.1007/s11214-010-9677-4

K.L. Robinson, J.J. Barnes, K. Nagashima et al., Water in evolved lunar rocks: evidence for multiple reservoirs. Geochim. Cosmochim. Acta 188, 244 (2016). https://doi.org/10.1016/j.gca.2016.05.030

L. Roth, Constraints on water vapor and sulfur dioxide at Ceres: exploiting the sensitivity of the Hubble Space Telescope. Icarus 305, 149-159 (2018). https://doi.org/10.1016/j.icarus.2018.01.011

L. Roth, N. Ivchenko, K.D. Retherford et al., Constraints on an exosphere at Ceres from Hubble Space Telescope observations. Geophys. Res. Lett. 43, 2465-2472 (2016). https://doi.org/10.1002/2015GL067451

P. Rousselot, E. Jehin, J. Manfroid et al., A search for water vaporization on Ceres. Astron. J. 142, 125 (2011). https://doi.org/10.1088/0004-6256/142/4/125

P. Rousselot, C. Opitom, E. Jehin et al., Search for water outgassing of (1) Ceres near perihelion. Astron. Astrophys. 628, A22 (2019). https://doi.org/10.1051/0004-6361/201935738

L. Rubanenko, E. Mazarico, G.A. Neumann, D.A. Paige, Ice in micro cold traps on Mercury: implications for age and origin. J. Geophys. Res., Planets 123, 2178-2191 (2018). https://doi.org/10.1029/ 2018JE005644

L. Rubanenko, J. Venkatraman, D.A. Paige, Thick ice deposits in shallow simple craters on the Moon and Mercury. Nat. Geosci. 12(8), 597-601 (2019). https://doi.org/10.1038/s41561-019-0405-8

O. Ruesch, T. Platz, P. Schenk et al., Cryovolcanism on Ceres. Science 353, aaf4286 (2016). https://doi.org/ 10.1126/science.aaf4286

C.T. Russell, C.A. Raymond, E. Ammannito et al., Dawn arrives at Ceres: exploration of a small, volatile-rich world. Science 353, 1008-1010 (2016). https://doi.org/10.1126/science.aaf4219

A.E. Saal, E.H. Hauri, M.L. Cascio et al., Volatile content of lunar volcanic glasses and the presence of water in the Moon's interior. Nature 454, 192-195 (2008). https://doi.org/10.1038/nature07047

M.J. Schaible, R.A. Baragiola, Hydrogen implantation in silicates: the role of solar wind in $\mathrm{SiOH}$ bond formation on the surfaces of airless bodies in space. J. Geophys. Res., Planets 119, 2017 (2014). https:// doi.org/10.1002/2014JE004650

N. Schorghofer, Migration calculations for water in the exosphere of the Moon: dusk-dawn asymmetry, heterogeneous trapping, and D/H fractionation. Geophys. Res. Lett. 41, 4888-4893 (2014). https://doi.org/ 10.1002/2014GL060820

N. Schorghofer, Two-dimensional description of surface-bounded exospheres with application to the migration of water molecules on the Moon. Phys. Rev. E 91(5), 052154 (2015). https://doi.org/10.1103/ PhysRevE.91.052154

N. Schorghofer, Predictions of depth-to-ice on asteroids based on an asynchronous model of temperature, impact stirring, and ice loss. Icarus 276, 88-95 (2016). https://doi.org/10.1016/j.icarus.2016.04.037

N. Schorghofer, O. Aharonson, The lunar thermal ice pump. Astrophys. J. 788(2), 169 (2014). https://doi.org/ 10.1088/0004-637X/788/2/169

N. Schorghofer, G.J. Taylor, Subsurface migration of $\mathrm{H}_{2} \mathrm{O}$ at lunar cold traps. J. Geophys. Res., Planets 112(E2), E02010 (2007). https://doi.org/10.1029/2006JE002779

N. Schorghofer, J.P. Williams, Mapping of ice storage processes on the Moon with time-dependent temperatures. Planet. Sci. J. 1, 54 (2020). https://doi.org/10.3847/PSJ/abb6ff

N. Schorghofer, E. Mazarico, T. Platz et al., The permanently shadowed regions of dwarf planet Ceres. Geophys. Res. Lett. 43, 6783-6789 (2016). https://doi.org/10.1002/2016GL069368

N. Schorghofer, S. Byrne, M.E. Landis et al., The putative cerean exosphere. Astrophys. J. 850, 85 (2017a). https://doi.org/10.3847/1538-4357/aa932f

N. Schorghofer, P. Lucey, J.P. Williams, Theoretical time variability of mobile water on the Moon and its geographic pattern. Icarus 298, 111-116 (2017b). https://doi.org/10.1016/j.icarus.2017.01.029

S.E. Schröder, S. Mottola, U. Carsenty et al., Resolved spectrophotometric properties of the Ceres surface from Dawn Framing Camera images. Icarus 288, 201-225 (2017). https://doi.org/10.1016/j.icarus.2017. 01.026

P.H. Schultz, L.J. Srnka, Cometary collisions on the moon and Mercury. Nature 284, 22-26 (1980). https:// doi.org/10.1038/284022a0 
V.V. Shevchenko, Observable evidence for cometary impacts on the Moon and their age. Astron. Rep. 37(3), 314-319 (1993)

R.A. Simpson, G.L. Tyler, Reanalysis of Clementine bistatic radar data from the lunar south pole. J. Geophys. Res., Planets 104(E2), 3845-3862 (1999). https://doi.org/10.1029/1998JE900038

H. Sizemore, B.E. Schmidt, D.A. Buczkowski et al., A global inventory of ice-related morphological features on dwarf planet Ceres: implications for the evolution and current state of the cryosphere. J. Geophys. Res., Planets 124, 1650-1689 (2019). https://doi.org/10.1029/2018JE005699

M.A. Slade, B.J. Butler, D.O. Muhleman, Mercury radar imaging: evidence for polar ice. Science 258, 635-639 (1992). https://doi.org/10.1126/science.258.5082.635

R. Sridharan, S.M. Ahmed, T.P. Das, P. Sreelatha, P. Pradeepkumar, N. Naik, G. Supriya, The sunlit lunar atmosphere: A comprehensive study by CHACE on the Moon Impact Probe of Chandrayaan-1. Planet. Space Sci. 58(12), 1567-1577 (2010). https://doi.org/10.1016/j.pss.2010.07.027

R. Sridharan, S.M. Ahmed, T.P. Das, P. Sreelatha, P. Pradeepkumar, N. Naik, G. Supriya, Corrigendum to "The sunlit lunar atmosphere: a comprehensive study by CHACE on the Moon Impact Probe of Chandrayaan-1". Planet. Space Sci. 111, 167-168 (2015). https://doi.org/10.1016/j.pss.2014.12.021. [Planet. Space Sci. 58, 1567-1577 (2010)]

N.J.S. Stacy, D.B. Campbell, P.G. Ford, Arecibo radar mapping of the lunar poles: a search for ice deposits. Science 276(5318), 1527-1530 (1997). https://doi.org/10.1126/science.276.5318.1527

L.V. Starukhina, Water detection on atmosphereless celestial bodies: alternative explanations of the observations. J. Geophys. Res., Planets 106(E7), 14701-14710 (2001). https://doi.org/10.1029/2000JE001307

L.V. Starukhina, Polar regions of the Moon as a potential repository of solar-wind-implanted gases. Adv. Space Res. 37(1), 50-58 (2006). https://doi.org/10.1016/j.asr.2005.04.033

L.V. Starukhina, Water on the Moon: what is derived from the observations? in The Moon: Prospective Energy and Material Resources, ed. by V. Badescu (Springer, Berlin, 2012), pp. 57-85. https://doi.org/10.1007/ 978-3-642-27969-0_3

L.V. Starukhina, Y.G. Shkuratov, The lunar poles: water ice or chemically trapped hydrogen? Icarus $\mathbf{1 4 7}(2)$, 585-587 (2000). https://doi.org/10.1006/icar.2000.6476

A. Stephant, F. Robert, The negligible chondritic contribution in the lunar soils water. Proc. Natl. Acad. Sci. 111(42), 15007-15012 (2014). https://doi.org/10.1073/pnas.1408118111

S.A. Stern, The lunar atmosphere: history, status, current problems, and context. Rev. Geophys. 37(4), 453-491 (1999). https://doi.org/10.1029/1999RG900005

S.A. Stern, J.C. Cook, J.Y. Chaufray et al., Lunar atmospheric $\mathrm{H}_{2}$ detections by the LAMP UV spectrograph on the Lunar Reconnaissance Orbiter. Icarus 226(2), 1210-1213 (2013). https://doi.org/10.1016/j.icarus. 2013.07.011

B.D. Stewart, E. Pierazzo, D.B. Goldstein, P.L. Varghese, L.M. Trafton, Simulations of a comet impact on the Moon and associated ice deposition in polar cold traps. Icarus 215(1), 1-16 (2011). https://doi.org/ 10.1016/j.icarus.2011.03.014

M. Stirniman, C. Huang, R. Scott Smith, S. Joyce, B.D. Kay, The adsorption and desorption of water on single crystal MgO (100): the role of surface defects. J. Chem. Phys. 105, 1295 (1996). https://doi.org/ $10.1063 / 1.471993$

J.D. Stopar, B.L. Jolliff, E.J. Speyerer, E.I. Asphaug, M.S. Robinson, Potential impact-induced water-solid reactions on the Moon. Planet. Space Sci. 162, 157-169 (2018). https://doi.org/10.1016/j.pss.2017.05. 010

J.M. Sunshine, T.L. Farnham, L.M. Feaga, O. Groussin, F. Merlin, R.E. Milliken, M.F. A'Hearn, Temporal and spatial variability of lunar hydration as observed by the Deep Impact Spacecraft. Science 326(5952), 565-568 (2009). https://doi.org/10.1126/science.1179788

H.C. Susorney, P.B. James, C.L. Johnson et al., The thickness of radar-bright deposits in Mercury's northern hemisphere from individual Mercury Laser Altimeter tracks. Icarus 323, $40-45$ (2019). https://doi.org/ 10.1016/j.icarus.2019.01.016

S.V. Thampi, R. Sridharan, T.P. Das, S.M. Ahmed, J.A. Kamalakar, A. Bhardwaj, The spatial distribution of molecular hydrogen in the lunar atmosphere-new results. Planet. Space Sci. 106, 142-147 (2015). https://doi.org/10.1016/j.pss.2014.12.018

G. Thangjam, M. Hoffmann, A. Nathues et al., Haze at Occator crater on dwarf planet Ceres. Astrophys. J. Lett. 833, 2 (2016). https://doi.org/10.3847/2041-8213/833/2/L25

G.E. Thomas, Mercury: does its atmosphere contain water? Science 183(4130), 1197-1198 (1974). https:// doi.org/10.1126/science.183.4130.1197

L. Tu, W.-H. Ip, Y.-C. Wang, A sublimation-driven exospheric model of Ceres. Planet. Space Sci. 104, 157-162 (2014). https://doi.org/10.1016/j.pss.2014.09.002

O.J. Tucker, W.M. Farrell, R.M. Killen, D.M. Hurley, Solar wind implantation into the lunar regolith: Monte Carlo simulations of $\mathrm{H}$ retention in a surface with defects and the $\mathrm{H}_{2}$ exosphere. J. Geophys. Res., Planets 124(2), 278-293 (2019). https://doi.org/10.1029/2018JE005805 
O.J. Tucker, W.M. Farrell, A.R. Poppe, On the effect of magnetospheric shielding on the lunar hydrogen cycle. J. Geophys. Res., Planets 126, e2020JE006552 (2021). https://doi.org/10.1029/2020JE006552

H. Urey, The Planets, Their Origin and Development (Yale University Press, New Haven, 1952)

A.R. Vasavada, D.A. Paige, S.E. Wood, Near-surface temperatures on Mercury and the Moon and the stability of polar ice deposits. Icarus 141(2), 179-193 (1999). https://doi.org/10.1006/icar.1999.6175

A.R. Vasavada, J.L. Bandfield, B.T. Greenhagen, Lunar equatorial surface temperatures and regolith properties from the diviner lunar radiometer experiment. J. Geophys. Res., Planets 117(E12), E00H18 (2012). https://doi.org/10.1029/2011JE003987

M.N. Villarreal, C.T. Russell, J.G. Luhmann et al., The dependence of the cerean exosphere on solar energetic particle events. Astrophys. J. Lett. 838, L8 (2017). https://doi.org/10.3847/2041-8213/aa66cd

H. Wang, H.Z. Zhang, J. Shi et al., Earth wind as a possible exogenous source of lunar surface hydration. Astrophys. J. Lett. 907(2), L32 (2021). https://doi.org/10.3847/2041-8213/abd559

K. Watson, B. Murray, H. Brown, On the possible presence of ice on the Moon. J. Geophys. Res. 66, 1598-1600 (1961a). https://doi.org/10.1029/JZ066i005p01598

K. Watson, B. Murray, H. Brown, The behavior of volatiles on the lunar surface. J. Geophys. Res. 66, 3033-3045 (1961b). https://doi.org/10.1029/JZ066i009p03033

J.P. Williams, B.T. Greenhagen, D.A. Paige et al., Seasonal polar temperatures on the Moon. J. Geophys. Res., Planets 124(10), 2505-2521 (2019). https://doi.org/10.1029/2019JE006028

C. Wöhler, A. Grumpe, A.A. Berezhnoy, E.A. Feoktistova, N.A. Evdokimova, K. Kapoor, V.V. Shevchenko, Temperature regime and water/hydroxyl behavior in the crater Boguslawsky on the Moon. Icarus 285, 118-136 (2017a). https://doi.org/10.1016/j.icarus.2016.12.026

C. Wöhler, A. Grumpe, A.A. Berezhnoy, V.V. Shevchenko, Time-of-day-dependent global distribution of lunar surficial water/hydroxyl. Sci. Adv. 3(9), 1-11 (2017b). https://doi.org/10.1126/sciadv.1701286

Y. Wu, B. Hapke, Spectroscopic observations of the Moon at the lunar surface. Earth Planet. Sci. Lett. 484, 145-153 (2018). https://doi.org/10.1016/j.epsl.2017.12.003

E.J. Zeller, L.B. Ronca, P.W. Levy, Proton-induced hydroxyl formation on the lunar surface. J. Geophys. Res. 71(20), 4855-4860 (1966). https://doi.org/10.1029/JZ071i020p04855

X. Zeng, H. Tang, X.Y. Li, X. Zeng, Y. Wen, J. Liu, Y. Zou, Experimental investigation of OH/ $\mathrm{H}_{2} \mathrm{O}$ in $\mathrm{H}^{+}$irradiated plagioclase: implications for the thermal stability of water on the lunar surface. Earth Planet. Sci. Lett. 560, 116806 (2021). https://doi.org/10.1016/j.eps1.2021.116806

J.A. Zhang, D.A. Paige, Cold-trapped organic compounds at the poles of the Moon and Mercury: Implications for origins. Geophys. Res. Lett. 36(16), L16203 (2009). https://doi.org/10.1029/2009GL038614

C. Zhu, P.B. Crandall, J.J. Gillis-Davis, H.A. Ishii, J.P. Bradley, L.M. Corley, R.I. Kaiser, Untangling the formation and liberation of water in the lunar regolith. Proc. Natl. Acad. Sci. 116, 11165-11170 (2019). https://doi.org/10.1073/pnas.1819600116

C. Zhu, S. Góbi, M.J. Abplanalp et al., Regenerative water sources on surfaces of airless bodies. Nat. Astron. 4(1), 45-52 (2020). https://doi.org/10.1038/s41550-019-0900-2

Publisher's Note Springer Nature remains neutral with regard to jurisdictional claims in published maps and institutional affiliations.

\section{Authors and Affiliations}

\section{Norbert Schörghofer ${ }^{1,2}$ (D) $\cdot$ Mehdi Benna $^{3}$ (D) A Alexey A. Berezhnoy ${ }^{4,5}$ (D) Benjamin Greenhagen ${ }^{6}$ (D) $\cdot$ Brant M. Jones $^{7}$ (D) Shuai $\mathrm{Li}^{8}$ (D) Thomas M. Orlando $^{7}$ (D) . Parvathy Prem $^{6}$ (D) Orenthal J. Tucker $^{3}$ (D) Christian Wöhler ${ }^{9}$}

N. Schörghofer

norbert@psi.edu

1 Planetary Science Institute, Tucson, AZ, USA

2 Planetary Science Institute, Honolulu, HI, USA

3 NASA Goddard Space Flight Center, Greenbelt, MD, USA

4 Moscow State University, Moscow, Russia

5 Kazan Federal University, Kazan, Russia 
6 Johns Hopkins Applied Physics Laboratory, Laurel, MD, USA

7 School of Chemistry and Biochemistry, Georgia Institute of Technology, Atlanta, GA, USA

8 Hawaii Institute of Geophysics and Planetology, University of Hawaii, Honolulu, HI, USA

9 Image Analysis Group, Technical University of Dortmund, Dortmund, Germany 